\title{
DOE/ER/82763-2
}

\section{A GENERIC APPROACH TO IMPROVED SEMI-SOLID FORMING OF METALS}

Final Report

For Period June 6, 2000 - June 5, 2002

Eric M. Klier

Chesapeake Composites Corporation

239 Old Churchmans Road

New Castle, DE 19720

June 2002

Prepared for

THE U.S. DEPARTMENT OF ENERGY

Under Award Number DE-FG02-99ER82763 


\section{DISCLAMMER}

This report was prepared as an account of work sponsored by an agency of the United States Government. Neither the United States Governmeat nor any agency thereof, nor any of their employees, makes any warranty, express or implied, or assumes any legal liability or responsibility for the accuracy, completeness, or usefulness of any information, apparatus, product, or process disclosed, or represents that its use would not infringe privately owned rights. Reference berein to any specific commercial product, process, or service by trade name, trademark, manufacturer, or otherwise does not necessarily constitute or imply its endorsement, recommendation, or favoring by the United States Government or any agency thereof. The views and opinions of authors expressed herein do not necessarily state or refleet those of the United States Government or any agency thereof. 


\section{DISCLAIMER}

Portions of this document may be illegible in electronic image products. Images are produced from the best available original document. 


\section{NOTICE}

This report was prepared as an account of work sponsored by the United States Government. Neither the United States nor the United States Department of Energy, nor any of their employees, nor any of their awardees, subcontractors, or their employees, makes any warranty, express or implied, or assumes any legal liability or responsibility for the accuracy, completeness, or usefulness of any information, apparatus, product or process disclosed or represents that its use would not infringe privately-owned rights. 


\begin{abstract}
$\underline{\text { Abstract }}$
Chesapeake has developed a manufacturing approach for scale-up to 6" diameter billets. This approach has been inserted into an extant ceramic manufacturing facility to yielding a plant with the capability of up to 5 million pounds per year of billets up to 6 " in diameter. The manufacturing approach is summarized as follows:
\end{abstract}

- Aqueous ball milling for the production of a ceramic slurry

- Spray drying for the formation of a free flowing powder for pressing

- Isostatic pressing for the formation of large cylindrical preforms

- Burnout and firing in air kilns

- Liquid metal infiltration using vertical squeeze infiltration press

All process steps utilize commercially available equipment that operates continuously or in large batches. Furthermore, the process steps are highly automated and coordinated for reduced labor costs, inventory costs and to minimize cycle time.

Finally, the results of the 4" diameter billet work and the manufacturing approach were incorporated into Chesapeake's existing cost model to evaluate the primary processing costs at the 4" diameter billet level. Results of the cost model indicate that the cost/lb. to manufacture DSC $^{\text {TM }}$ Aluminum billet is consistent with the market interest (what customers are willing to pay) for the product.

\title{
Materials and experimental techniques
}

Three composite castings and one ceramic preform were evaluated. Two of the castings are very similar in terms of volume fraction ceramic while the third has a slightly higher volume fraction. In what follows, these materials will be designated as $\mathrm{Cla}, \mathrm{Clb}$, and $\mathrm{C} 2$, respectively. The ceramic preform corresponds to the $\mathrm{C} 1$ castings and will be designated P1.

Optical Microscopy (OM) and Scanning Electron Microscopy (SEM) were used to characterize the microstructures of as-cast composites after standard diamond-based metallographic preparation techniques. For SEM imaging, a final electropolishing step was introduced ( $3 \mathrm{sec}$ at $50 \mathrm{~V}$ with Struers A2 electrolyte) after mechanical polishing in order to remove a layer of $\mathrm{Al}$ (which is preferentially electropolished) and reveal the reinforcement architecture within the composite (in the case of compressed samples it also helps to reveal any 
voids within the matrix of the composites produced during straining, which would not be discernable after simple mechanical polishing due to smearing of the soft $\mathrm{Al}$ matrix). High precision helium pycnometry was employed in determining the density of the as-cast composites. Volume fractions of ceramic in the as-cast materials were determined from these density measurements assuming no porosity and densities for bulk $\mathrm{Al}_{2} \mathrm{O}_{3}$ and $\mathrm{Al}$ of $3.97 \mathrm{~g} / \mathrm{cm}^{3}$ and $2.6989 \mathrm{~g} / \mathrm{cm}^{3}$, respectively.

Compressive testing was conducted on cylindrical samples $10 \mathrm{~mm}$ in diameter and $15 \mathrm{~mm}$ in height. It was experimentally determined that this specific sample geometry has the maximum aspect ratio for which no plastic buckling occurs. The samples were compressed between polished WC platens in a $100 \mathrm{kN}$ servohydraulic universal testing machine outfitted with a furnace and a controlled atmosphere chamber. Teflon was used as a lubricant between the sample and the platen surfaces up to $250^{\circ} \mathrm{C}$, while $\mathrm{BN}$ was used at higher temperatures.

For all experiments above room temperature the testing chamber was first evacuated and flushed with argon (to avoid oxidation of the WC platens), then heated at $10{ }^{\circ} \mathrm{C} / \mathrm{min}$ to the specific testing temperature and left to equilibrate for $45 \mathrm{~min}$ prior to testing. The rate of cooling of the chamber after testing is the same as the heating rate. The compressive behavior of the composites was determined at $25{ }^{\circ} \mathrm{C}, 250{ }^{\circ} \mathrm{C}, 500{ }^{\circ} \mathrm{C}, 600{ }^{\circ} \mathrm{C}, 670{ }^{\circ} \mathrm{C}$ and $720{ }^{\circ} \mathrm{C}$. Compressive tests were conducted on ceramic preforms prior to infiltration at $25^{\circ} \mathrm{C}, 600^{\circ} \mathrm{C}$, and $670{ }^{\circ} \mathrm{C}$.

In all compression tests, the machine was piloted under crosshead displacement control. Strain in the samples was determined from this displacement, corrected for the (temperaturedependent) compliance of the testing set-up. Measured strain-rates throughout a single test never vary by more than a factor of 1.3 . The strain rate-dependence of the composite flow curves was determined at $25{ }^{\circ} \mathrm{C}, 250^{\circ} \mathrm{C}$ and $670{ }^{\circ} \mathrm{C}$, and for nominal strain rates of $10^{-3} \mathrm{~s}^{-1}$, $10^{-2} \mathrm{~s}^{-1}, 10^{-1} \mathrm{~s}^{-1}$, and $10^{0} \mathrm{~s}^{-1}$.

The elastic constants of the as-cast composite samples (same sample geometry as for mechanical testing) were determined using an ultrasonic wave reflection technique. In particular, the speed of sound in the as-cast samples was determined using a $25 \mathrm{MHz}$ transducer linked to a digital oscilloscope.

In an attempt to study the effect of deformation history on the microstructure and the subsequent compressive response of the present composites the following experiments were conducted:

(i) dissolution of the composite matrix in a caustic solution (concentrated $\mathrm{NaOH}+$ $\mathrm{KOH}$ ) after different amounts of pre-strain at various testing temperatures

(ii) testing of the composites at $25^{\circ} \mathrm{C}, 250^{\circ} \mathrm{C}$, and $670{ }^{\circ} \mathrm{C}$ after a given amount of pre-strain at $500{ }^{\circ} \mathrm{C}$ 
(iii) testing of the composites at quasi-static strain rates $\left(10^{-3} \mathrm{~s}^{-1}\right)$ after pre-straining at higher strain rates $\left(10^{-1} \mathrm{~s}^{-1}\right.$ and $\left.10^{0} \mathrm{~s}^{-1}\right)$, and

(iv) determination of changes in the density and elastic constants of the composites as a result of deformation under various testing conditions. All of the above experiments are complemented by metallographic studies of deformed samples.

\section{Microstructure and physical properties}

As cast composite microstructures are characterized by a relatively homogeneous distribution of fine ceramic particles in a pore-free matrix, Fig. 1a. There seems to be a slight structuring of the composite on the intermediate scale; spheres of sintered particles on the order of $100 \mu \mathrm{m}$ in diameter (in comparison to the particles which are nominally $0.3 \mu \mathrm{m}$ in diameter), which are surrounded by channels of unreinforced $\mathrm{Al}$ matrix, can be seen in the OM of Fig. 1a, and at a higher magnification in the SEM, Fig. 1b. These spheres are probably a product of the freezedrying step during preform preparation. In Fig. $1 \mathrm{~b}$ one can also see that the reinforcing phase in the composites is interconnected which is a direct result of sintering of the ceramic preform prior to infiltration. In fact, the present composites have interpenetrating phase microstructures and are very similar to other interpenetrating phase composites (IPCs) found in literature.

The measured density and calculated ceramic volume fractions in the as-cast composites are given in Table 1. Values are averages of at least ten measurements. A variation in density from sample to sample, which is not statistical in nature, was noted: the density, and thus the ceramic volume fraction varies in the radial direction (perpendicular to the direction of infiltration), decreasing from the exterior to the interior of the casting. This variation is small, however, with a maximum measured difference on the order of 1.5 vol. $\% \mathrm{Al}_{2} \mathrm{O}_{3}$.

\section{Compressive behavior}

Curves displaying typical compressive responses of the present composites for various testing conditions are given in Fig. 2. Table 2 summarizes the results of the compression tests in terms of the peak stress attained, and the stress at $1 \%$ reference strain (given that the peak stress does not occur at a set strain for each testing condition). The elastic constants measured by ultrasonic vibration can be found in Table 1 . It should be noted that all plotted and tabulated values are absolute values of true stress and true strain.

General trends: The compressive flow stress of the present composites decreases as the temperature is increased to the melting point of the matrix. On the other hand, increasing the strain-rate serves to increase the compressive flow stress and this strain-rate dependence is greater at higher temperatures. The composites, thus, respond to variations in temperature and strain-rate in a manner similar to that observed for pure aluminum, usually understood in light of 
thermally activated components in dislocation motion. These findings are in agreement with the literature, in which composites with a strain-rate sensitive matrix are also found to be strain-rate sensitive (conversely, matrix metals that are not strain-rate sensitive typically result in composites that are not sensitive to strain-rate).

At temperatures above the melting point of the $\mathrm{Al}$ matrix, however, both the temperature and the strain-rate dependence of the flow stress disappear, within the experimental error of the measurements. In contrast, thixotropic materials display a decrease in flow stress with increasing strain rate, due to the competing processes of agglomeration and deagglomeration of the solid phase under the influence of strain. In the present materials, the solid phase deagglomerates under the influence of strain (see below) but there is no physical mechanism (such as local melting or "welding" of the solid phase in thixotropic alloy systems) to accommodate reagglomeration. It would seem that some solubility of the solid phase in the liquid is also necessary for agglomeration processes (or coarsening) to be operative on the time scale of straining. The rate of straining, thus, does not seem to be a determining parameter in the behavior of pure aluminum-matrix composites above the melting point of aluminum.

A common feature of all stress-strain curves is the existence of a peak stress after which the values of stress continuously decreases. This peak stress can be determined by taking the derivative of the stress-strain curve and finding its intersection with the stress-strain curve $(\mathrm{d} \sigma / \mathrm{d} \varepsilon=\sigma$, which is a geometric nstability criterion called the Considere criterion), Fig. 3 . Interestingly, the strain at which this peak stress (or "instability stress" according to the Considere criterion nomenclature) occurs is also a function of temperature and strain rate; it decreases with increasing temperature, Fig. 3 , and increases with increasing strain-rate.

Effect of volume fraction: The effect of varying the volume fraction ceramic in the investigated materials is noted both in Fig. 3 and Table 2; increasing their volume fraction serves to increase their compressive strength (material $\mathrm{Cla}$ and $\mathrm{C} 1 \mathrm{~b}$ versus $\mathrm{C} 2$ ). The fact that a difference in volume fraction of close to $2 \%$ can result in an increase in flow stress on the order of $25 \%$ (for the peak stress at $25^{\circ} \mathrm{C}$ and $10^{-3} \mathrm{~s}^{-1}$ ), indicates the importance of dispersion strengthening in the deformation behavior of these materials; dispersion strengthening is highly sensitive to the interparticle distance, $\lambda$, which in turn is sensitive to the volume fraction of particles (particularly in this high volume fraction regime).

Preform behavior: Compressive stress-strain curves of the ceramic preform prior to infiltration (P1) do not display significant variation between room temperature and $670{ }^{\circ} \mathrm{C}$, Fig. 4; an average compressive strength of $17 \mathrm{MPa}$ for the ceramic preforms was determined. This value is slightly higher but close to the average compressive strength of its corresponding composites (C1a and $\mathrm{C} 1 \mathrm{~b}$ ) above the melting point of the matrix, which is $9 \pm 2 \mathrm{MPa}$.

Macroscopic failure characteristics: Macroscopic fracture of the compressive samples at room temperature occurs shortly after the peak stress has been attained, through a single shear crack located at approximately $45^{\circ}$ to the compression axis. At temperatures above the melting 
point of $\mathrm{Al}$ multiple cracking occurs at precisely the maximum stress and these cracks are situated parallel to the compression axis and with a preference towards the exterior of the samples - a phenomenon very similar to spallation. At the intermediate temperatures of $250^{\circ} \mathrm{C}$ and $500{ }^{\circ} \mathrm{C}$, relatively large compressive strains (20-30\%) can be imposed on the samples without the appearance of macrocracks. The strains at which cracks fnally appear are much greater than the strain at which the peak stress occurs. These cracks are located on the surface of the midsection of the samples - probably a product of specimen barreling that is inevitable at large strains. At $600{ }^{\circ} \mathrm{C}$, the composites display no predominant fracture mode; cracks appear shortly after the peak stress either at $45^{\circ}$ or parallel to the compression axis. The described failure modes at a given temperature are not affected by the imposed strain rate. The preform, finally, fractures by the simultaneous propagation of several cracks with a mixed character; the cracks have segments both parallel and at a specific angle (not necessarily $45^{\circ}$ ) to the compression axis. Cracking occurs at precisely the maximum attained stress.

Dissolution experiments: The strain at which the maximum stress occurs was chosen as a reference strain; several samples from the three composite castings were quasistatically compressed $\left(10^{-3} \mathrm{~s}^{-1}\right)$ at various temperatures, to strains less than or greater than this reference strain. For samples that were deformed to strains greater than this reference strain (regardless of testing temperature and imposed strain rate), complete dissolution of the matrix was possible and the reinforcement settled to the bottom of the beaker, in which the dissolution took place, in the form of a powder; an indication that for those samples the reinforcement was no longer interconnected. For samples that were deformed to strains smaller than this reference strain, complete dissolution of the matrix was impossible and a residual inner core of metal was always present. In the exterior of the samples, however, were dissolution of the matrix did take place the reinforcement remained interconnected and there was no evidence of accumulated ceramic powder at the bottom of the beaker. The maximum in the compressive stress-strain curve of the present composites is, thus, somehow related to the loss of long-range interconnectivity of the reinforcing ceramic phase. Whether the loss of interconnectivity is a product of this peak stress or vice versa is not yet clear.

Effect of prestraining at a different temperature: Three samples from the $\mathrm{Cl}$ castings were deformed at $500{ }^{\circ} \mathrm{C}$ to strains slightly greater than the strain corresponding to the maximum stress (this temperature was chosen due to the low probability of macrocracking). After this prestraining, the samples were cooled down and subsequently tested at room temperature, 250 ${ }^{\circ} \mathrm{C}$ and $670{ }^{\circ} \mathrm{C}$. At all temperatures the prestrained samples join the compressive curves of ascast samples, which were monotonically tested at the same strain rate $\left(10^{-3} \mathrm{~s}^{-1}\right)$. This would indicate that for the given composite microstructure contiguity of the reinforcing phase plays a negligible role on plastic flow. It is rather the characteristic length scale of the microstructure (the interparticle distance for example), and its interaction with dislocation motion, which dominates the deformation behavior. This length scale should not change drastically with the loss of ceramic interconnectivity. Furthermore, the shape of the stress-strain curves of the prestrained samples is the same as those of the as-cast samples; a maximum in stress occurs after which the stress continuously decreases. This would seem to indicate that the maximum in the stress-strain 
curve does not occur due to the loss of interconnectivity of the reinforcement. Rather, another mechanism (or combination of mechanisms) becomes operative at that point leading to the breakdown of the ceramic network.

Whether or not interconnectivity of the ceramic phase influences the elastic constants of these materials is not yet clear-neither experimentally nor theoretically. Measurements of the elastic constants on three samples (one from each casting) deformed to $15 \%$ strain at $250^{\circ} \mathrm{C}$ revealed a 23\% decrease in the Young's modulus. These results are, however, non conclusive since this decrease in modulus was also accompanied by a decrease in density of the samples in the range of 0.6 and $0.9 \%$. This density decrease is primarily a product of microstructural damage accumulation in the form of matrix voiding, as revealed by SEM images of the compressed samples, Fig. 6. To distinguish the effects of interconnectivity and damage, we plan to determine the elastic constants of samples deformed to strains only slightly greater than the strain at which the maximum stress occurs (roughly $3 \%$ at temperatures between $250^{\circ} \mathrm{C}$ and $500^{\circ} \mathrm{C}$ ). At such small strains, the amount of accumulated damage is expected to be minimal.

Strain rate history effects: Samples of casting $\mathrm{Cla}$ and $\mathrm{Clb}$ where compressed at $250{ }^{\circ} \mathrm{C}$, initially under high strain rate conditions $\left(10^{-1} \mathrm{~s}^{-1}\right.$ and $\left.10^{0} \mathrm{~s}^{-1}\right)$, immediately followed by quasistatic reloading $\left(10^{-3} \mathrm{~s}^{-1}\right)$, Fig. 7. The differences between the flow stress of the reloaded samples and the uninterrupted quasistatic flow stress are small; however, the flow curves of the reloaded specimens tend to be somewhat lower than in the as-cast sample. Similarly, a sample reloaded at $250{ }^{\circ} \mathrm{C}$ after deforming at room temperature and thus at higher stress, displayed a lower flow stress compared to quasistatic loading at $250^{\circ} \mathrm{C}$, Fig. 7. One possible explanation for both of these observations is that damages accumulates with strain and is dependent on the flow stress.

\section{Conclusions:}

- Materials produced by infiltration of sintered $\mathrm{Al}_{2} \mathrm{O}_{3}$ preforms by liquid $\mathrm{Al}$ are homogeneous both macroscopically and microscopically. However, they display a certain amount of structuring on the meso-scale; in the form of spherical sintered bodies on the order of $100 \mu \mathrm{m}$, which are surrounded by unreinforced Al "veins".

- These materials are strain-rate dependent at room temperature and at $250{ }^{\circ} \mathrm{C}$, their strainrate sensitivity being higher at higher temperatures. Above the melting point of the matrix, and thus in the semi-solid state, this strain-rate dependency disappears. In other words, these materials do not appear to be thixotropic. The stresses needed to deform them in the semi-solid state are relatively low (10MPa), but cracking is evident early on in the deformation history. It is worth stressing, however, that these are results for testing under a uniaxial pressure and it is unclear what the effect of a superimposed hydrostatic pressure (common in thixoforming or any forming process) would be. 
- The fact that the reinforcement in these materials is interconnected has no bearing on their flow behavior in both the solid and the semi-solid state. Disnuption of this interconnectivity during straining or forming should not affect the mechanical properties of these composites at low or high temperature.

- Damage accumulates during plastic deformation of the composites primarily in the form of matrix voids, and the amount of damage seems to depend on flow stress (and thus strain rate). 
Tables and Figures

Table 1: Density, volume fraction ceramic and elastic constants

\begin{tabular}{|c|c|c|c|c|}
\cline { 2 - 5 } \multicolumn{1}{c|}{} & $\rho\left(\mathrm{g} / \mathrm{cm}^{3}\right)$ & $\mathrm{V}_{\mathrm{p}}(\%)$ & $\mathrm{E}(\mathrm{GPa})$ & $v(-)$ \\
\hline $\mathrm{C} 1 \mathrm{a}$ & $3.135( \pm 0.004)$ & 34.4 & 128 & 0.29 \\
\hline $\mathrm{C} 1 \mathrm{~b}$ & $3.138( \pm 0.005)$ & 34.6 & 129 & 0.3 \\
\hline $\mathrm{C} 2$ & $3.158( \pm 0.001)$ & 36.1 & 129 & 0.31 \\
\hline
\end{tabular}

Table 2: Compressive flow stress (average of three tests, error bars are on the plots that follow)

\begin{tabular}{|c|c|c|c|c|c|c|}
\cline { 2 - 7 } \multicolumn{1}{c|}{} & \multicolumn{2}{c|}{$\mathrm{Cla}$} & \multicolumn{2}{c|}{$\mathrm{C} 1 \mathrm{~b}$} & \multicolumn{2}{c|}{$\mathrm{C} 2$} \\
\hline $\mathrm{T}\left({ }^{\circ} \mathrm{C}\right)-\mathrm{d} \varepsilon / \mathrm{dt}\left(\mathrm{s}^{-1}\right)$ & $\sigma_{\max }(\mathrm{MPa})$ & $\sigma_{1 \%}(\mathrm{MPa})$ & $\sigma_{\max }(\mathrm{MPa})$ & $\sigma_{1 \%}(\mathrm{MPa})$ & $\sigma_{\max }(\mathrm{MPa})$ & $\sigma_{1 \%}(\mathrm{MPa})$ \\
\hline $25-10^{-3}$ & 475 & 395 & 454 & 385 & 595 & 546 \\
\hline $25-10^{-2}$ & 490 & 410 & - & - & 612 & 550 \\
\hline $25-10^{-1}$ & 492 & 418 & 461 & 400 & 638 & 590 \\
\hline $25-10^{0}$ & 509 & 428 & 480 & 422 & 700 & 626 \\
\hline $250-10^{-3}$ & 255 & 222 & 297 & 249 & 362 & 326 \\
\hline $250-10^{-2}$ & 297 & 260 & 315 & 278 & - & - \\
\hline $250-10^{-1}$ & - & - & 349 & 294 & - & - \\
\hline $250-10^{0}$ & 393 & 327 & 403 & 346 & - & - \\
\hline $500-10^{-3}$ & 84 & 82 & - & - & 112 & 110 \\
\hline $600-10^{-3}$ & 46 & 45 & 34 & 30 & 85 & 82 \\
\hline $670-10^{-3}$ & 9 & 9 & 9 & 9 & 19 & 19 \\
\hline $670-10^{-1}$ & 10 & 10 & - & - & - & - \\
\hline $670-10^{0}$ & 7.5 & 7.5 & - & - & - & - \\
\hline $720-10^{-3}$ & 7 & 7 & - & - & - & - \\
\hline
\end{tabular}


(a)

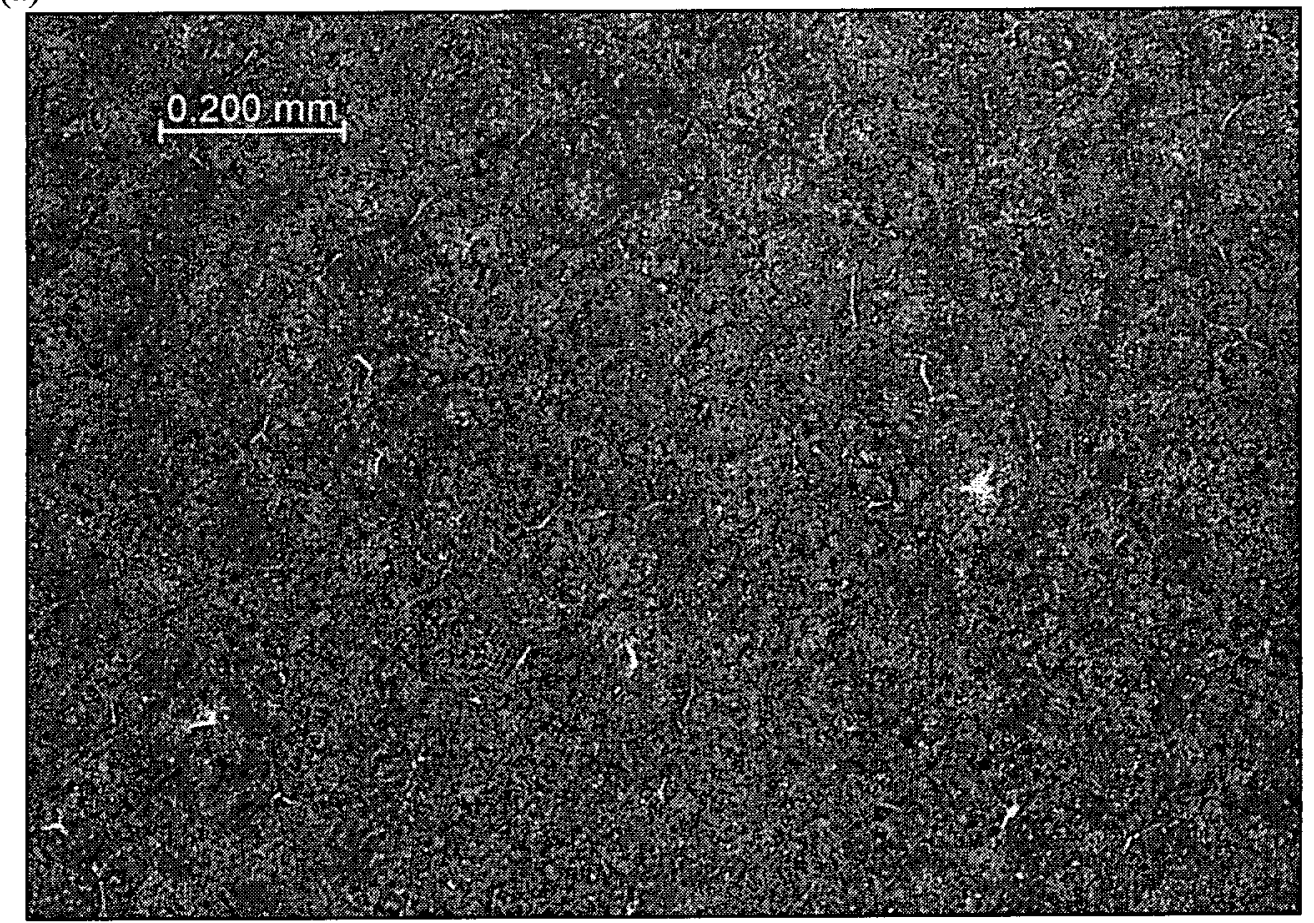

(b)

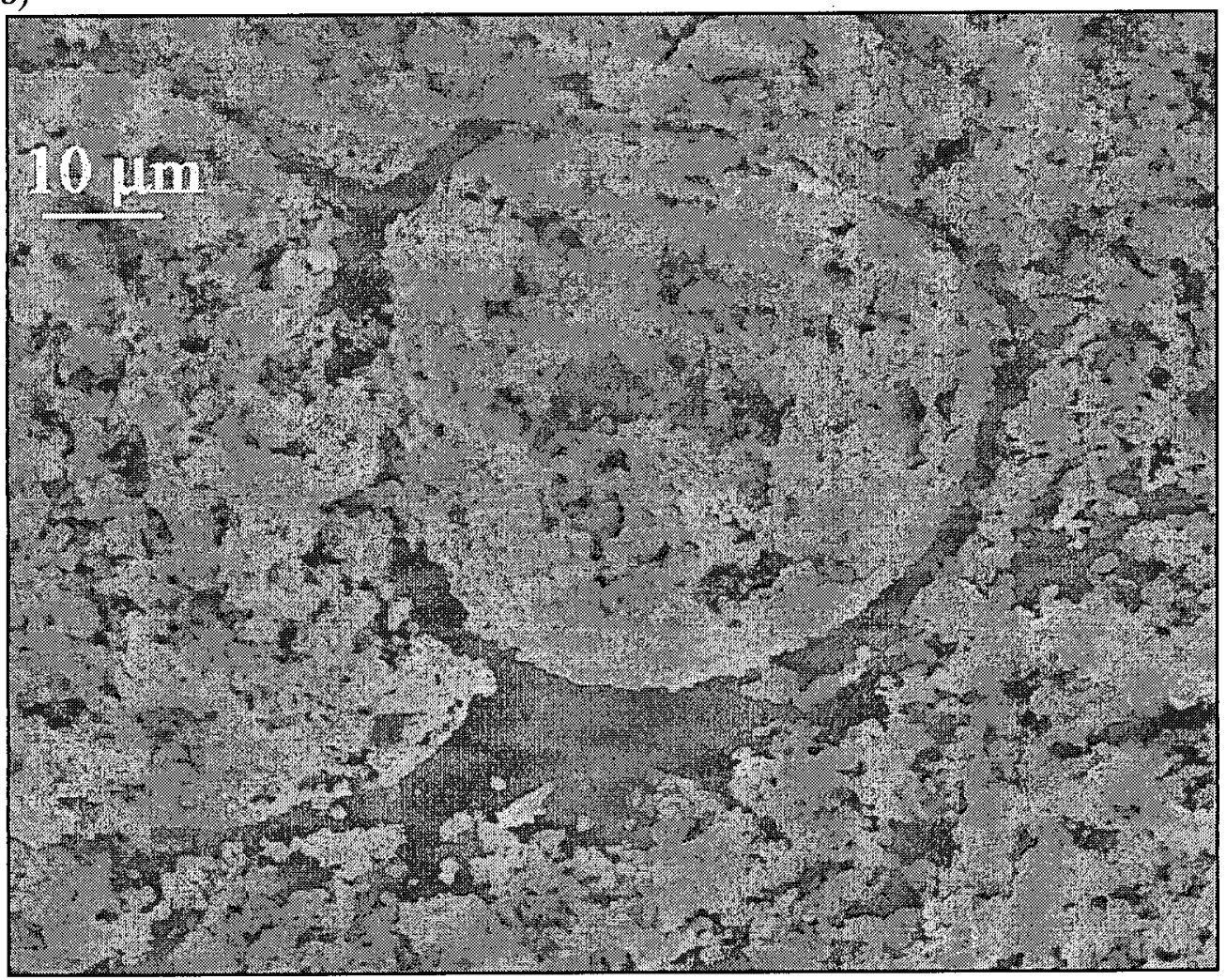

Figure 1: Microstructure of as-cast composite $\mathrm{Clb}$; (a) optical micrograph ( $\mathrm{Al}$ is the lighter phase) and (b) scanning electron micrograph ( $\mathrm{Al}$ is the darker phase). 
(a)

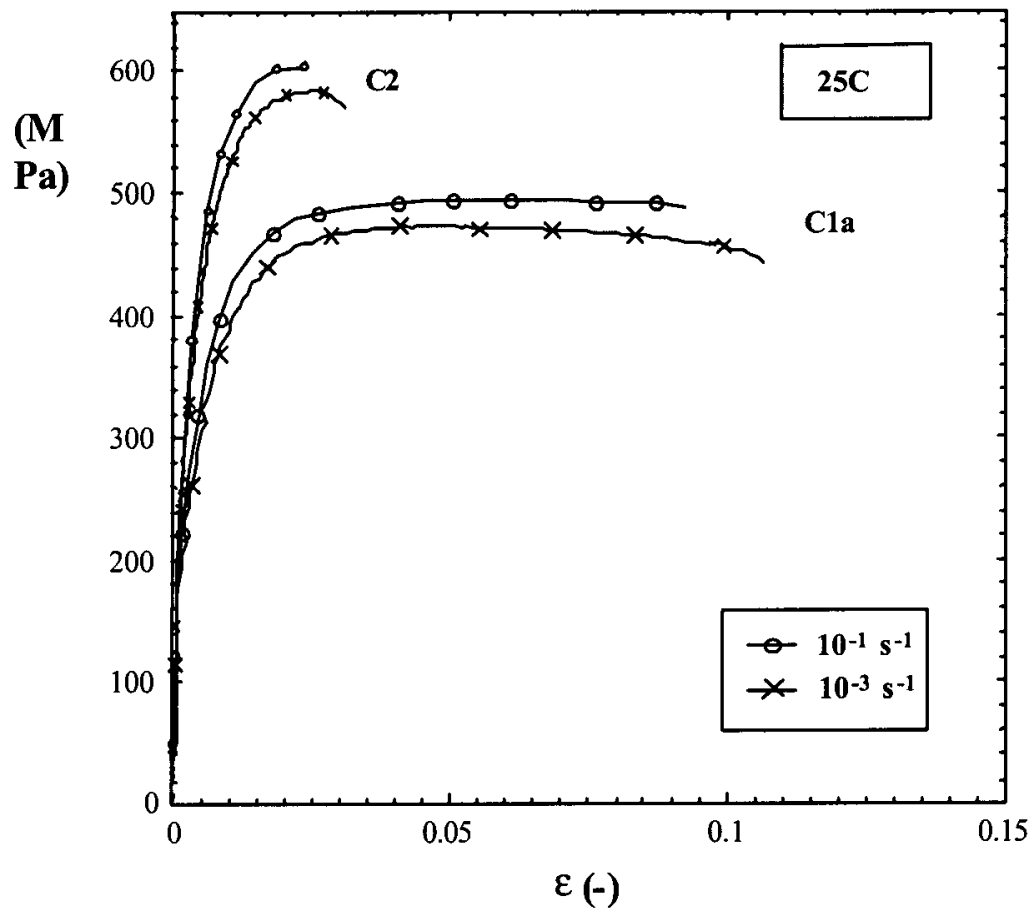

(b)

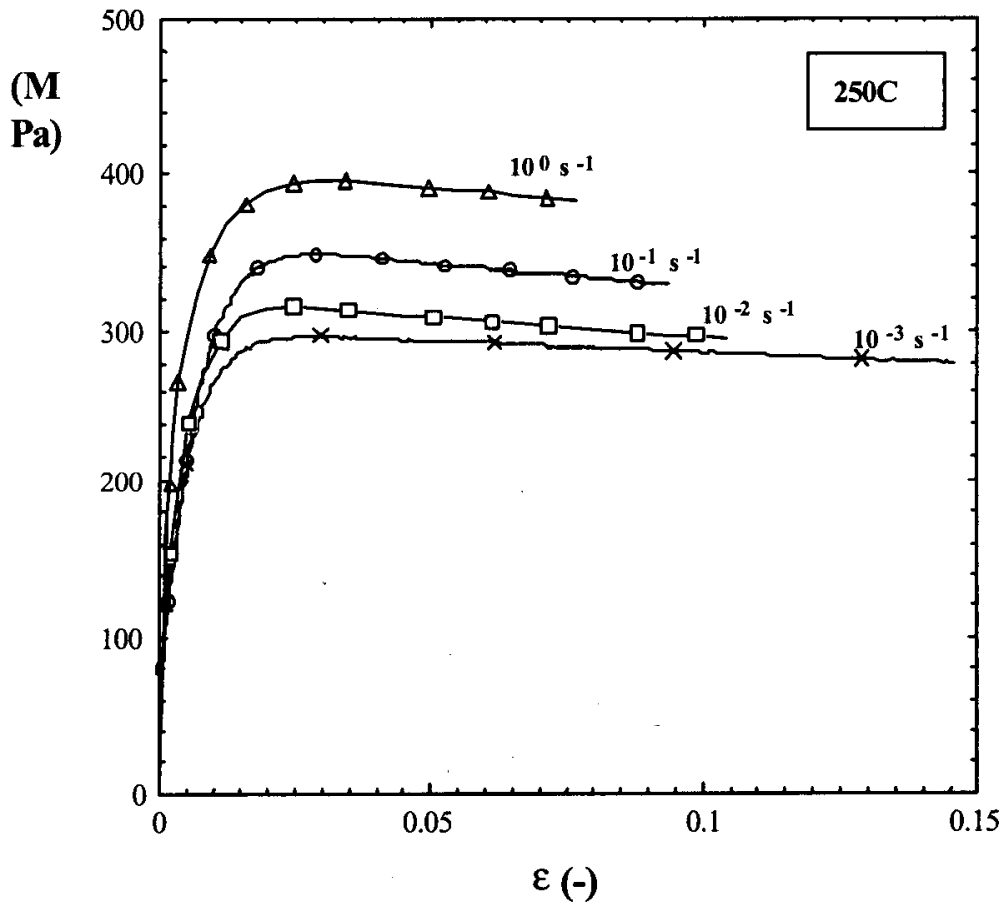

Figure 2: (a) Typical flow curves for composites $\mathrm{C} 1$ and $\mathrm{C} 2$ at room temperature and (b) effect of strain-rate on compressive behavior of composite $\mathrm{C} 1 \mathrm{~b}$ at $250{ }^{\circ} \mathrm{C}$. 
(c)

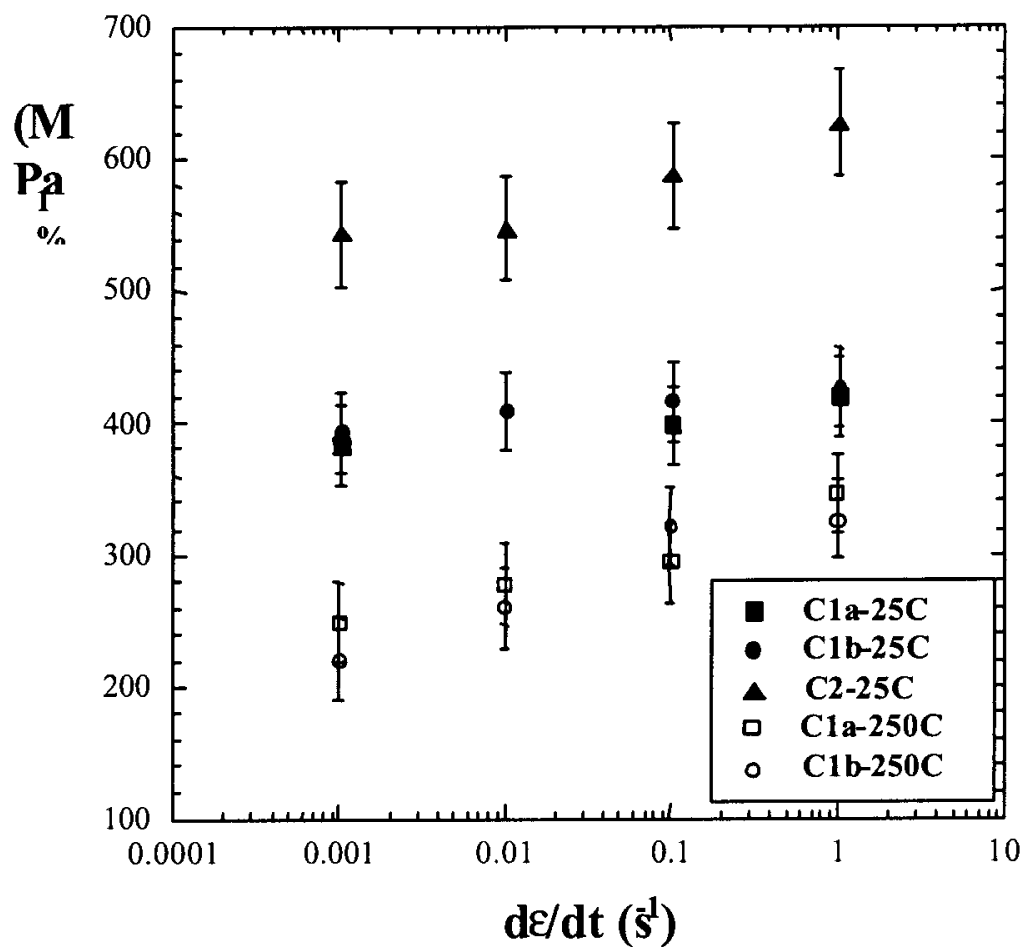

(d)

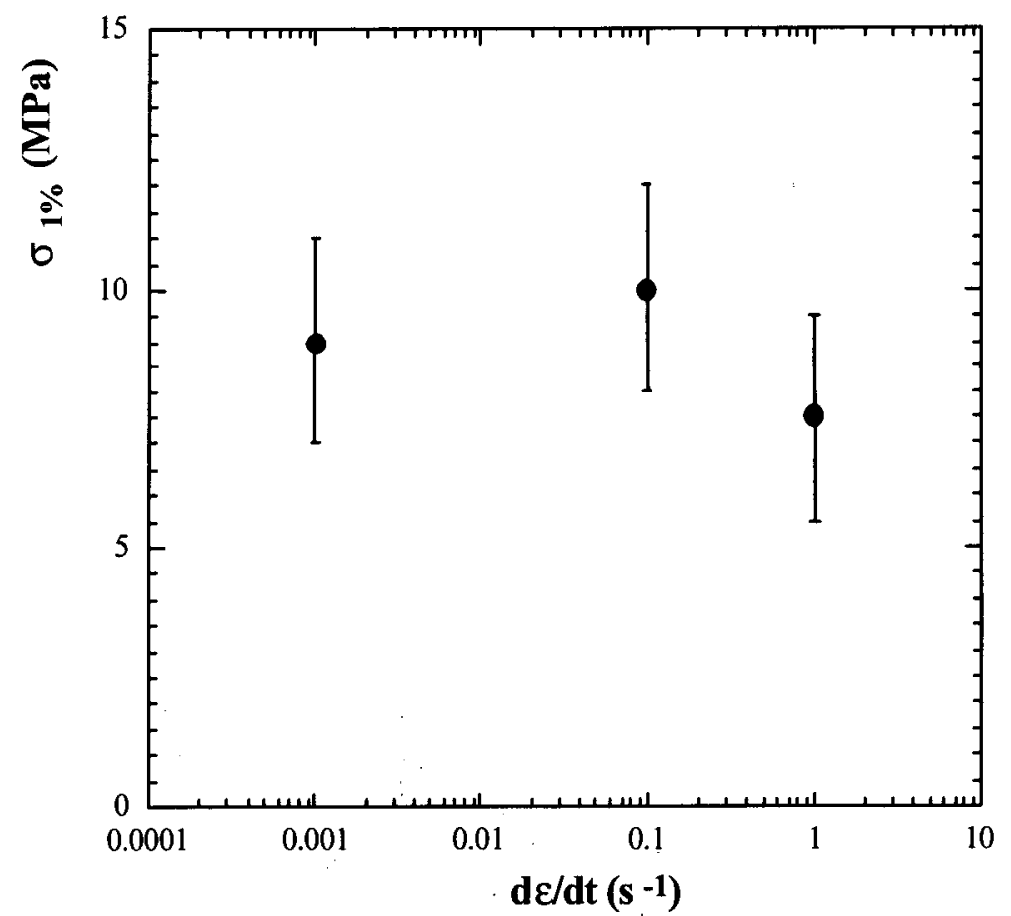

Figure 2 (cont'd): (c) strain rate effect on the composites at $25^{\circ} \mathrm{C}$ and $250^{\circ} \mathrm{C}$, and (d) strainrate effect at $670^{\circ} \mathrm{C}$ for composite $\mathrm{Cla}$. 
(e)

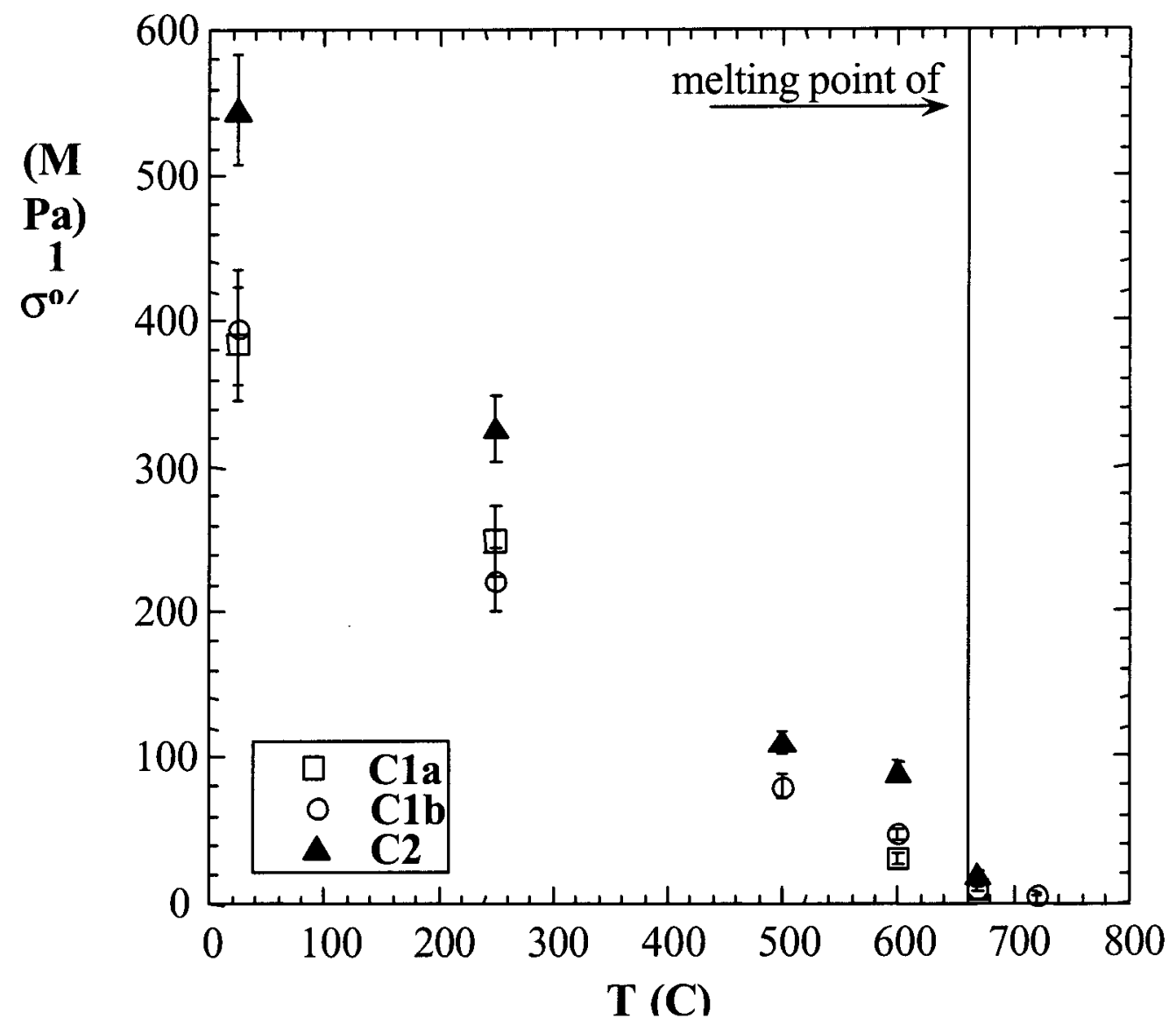

Figure 2 (cont'd): (e) effect of temperature on the quasi-static compressive flow behavior of the composites. 


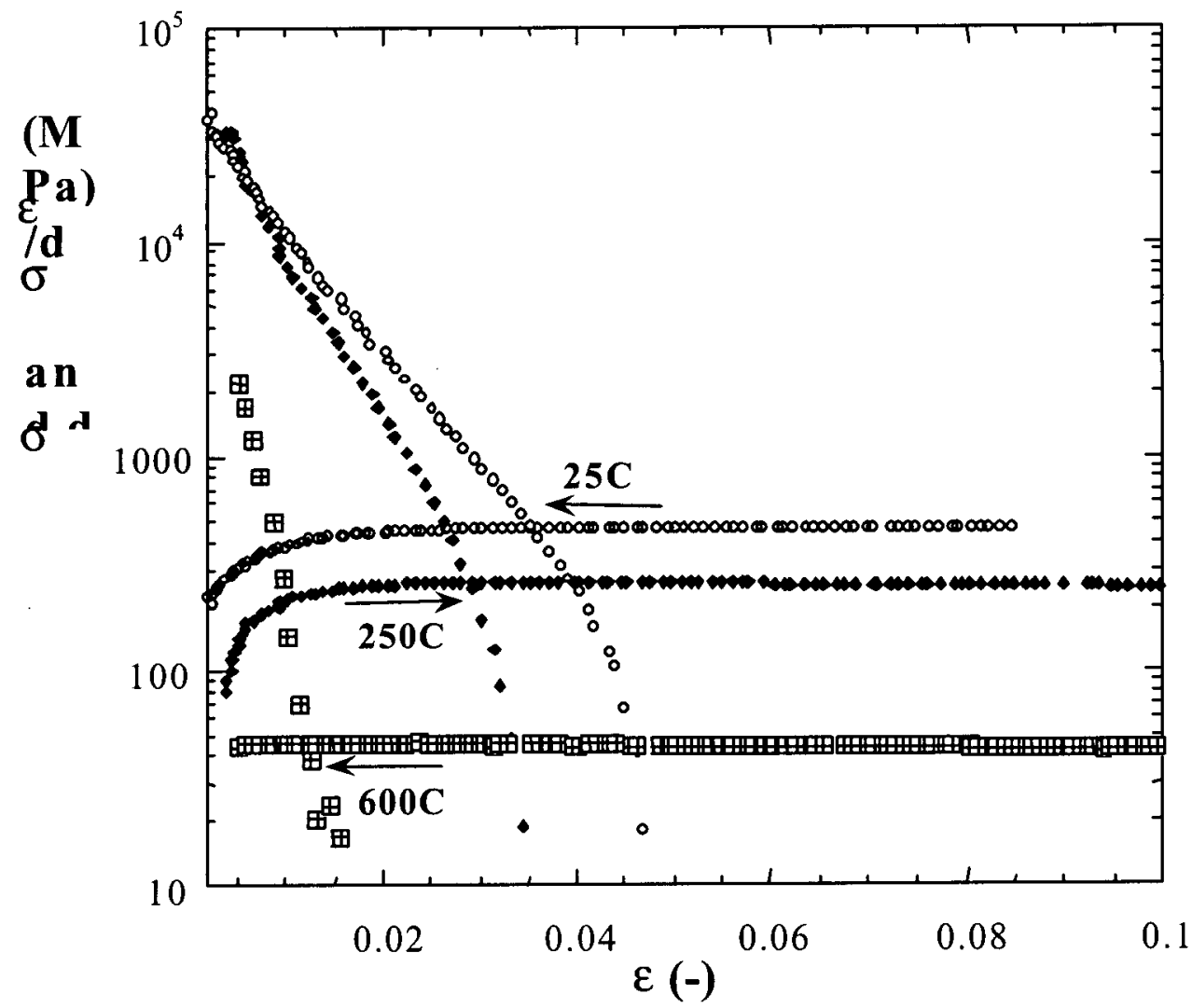

Figure 3: Stress-strain curves and their derivatives for composite Cla at various temperatures. 


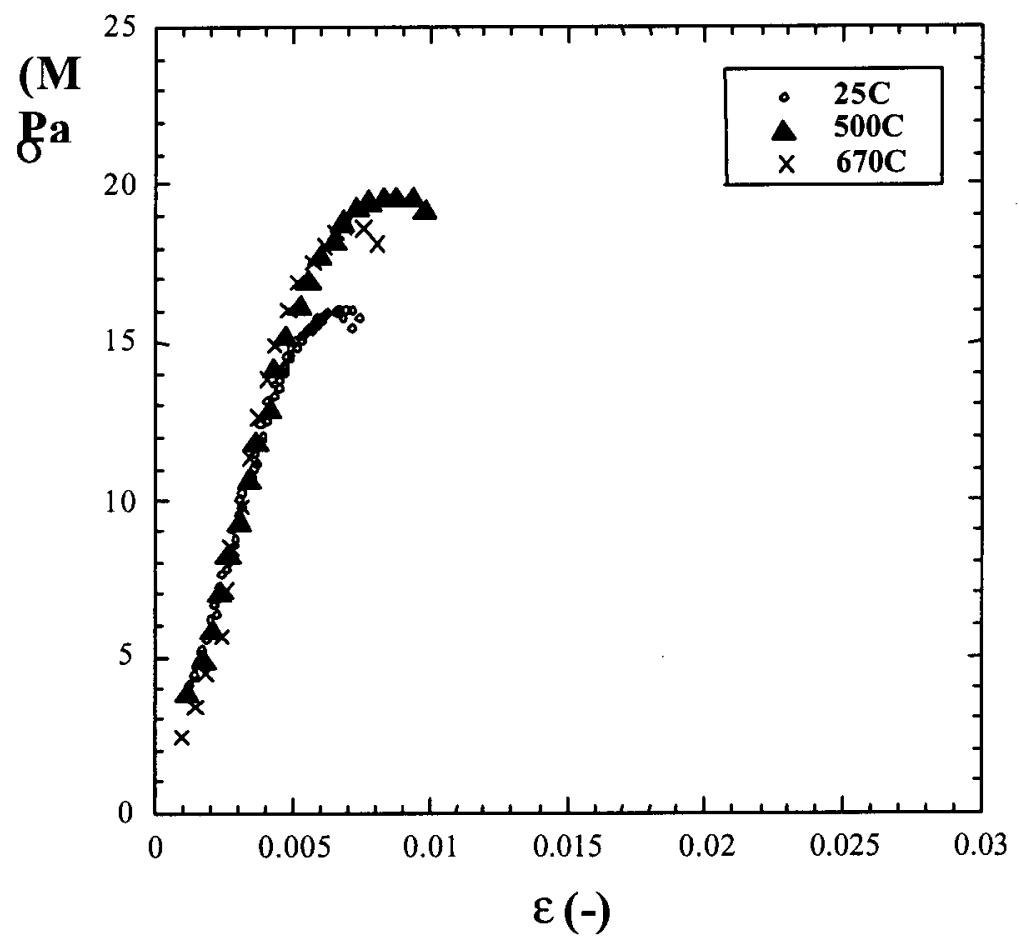

Figure 4: Compressive stress-strain curves of ceramic preform P1. 


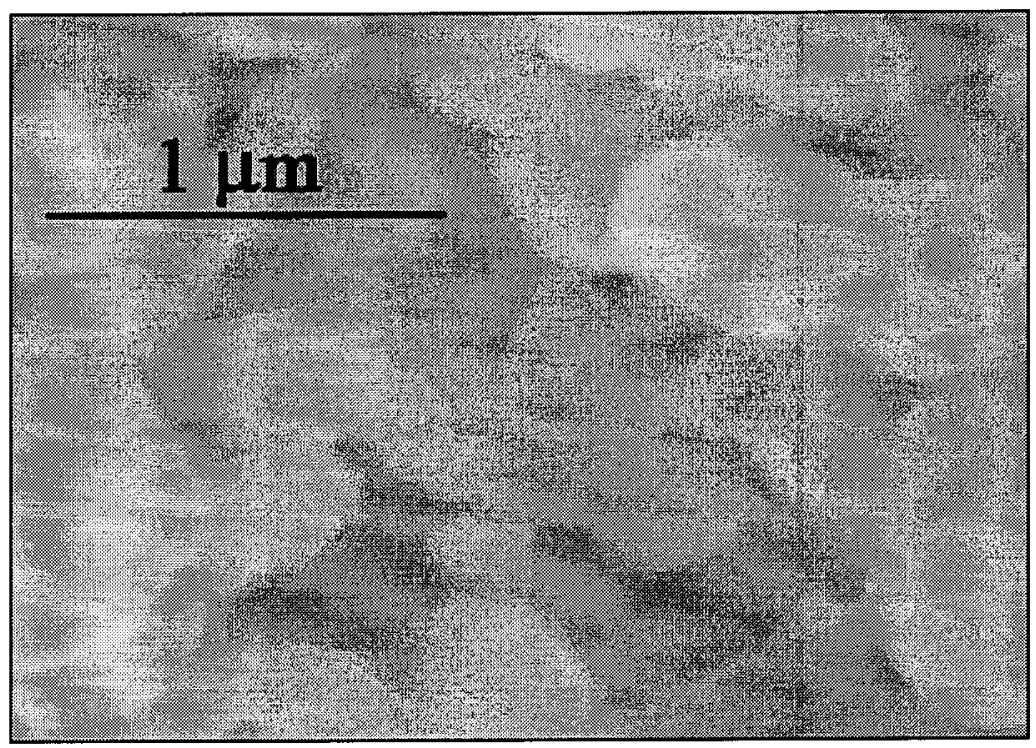

Figure 6: Matrix voiding after plastic straining at $250^{\circ} \mathrm{C}$ in composite Cla. 


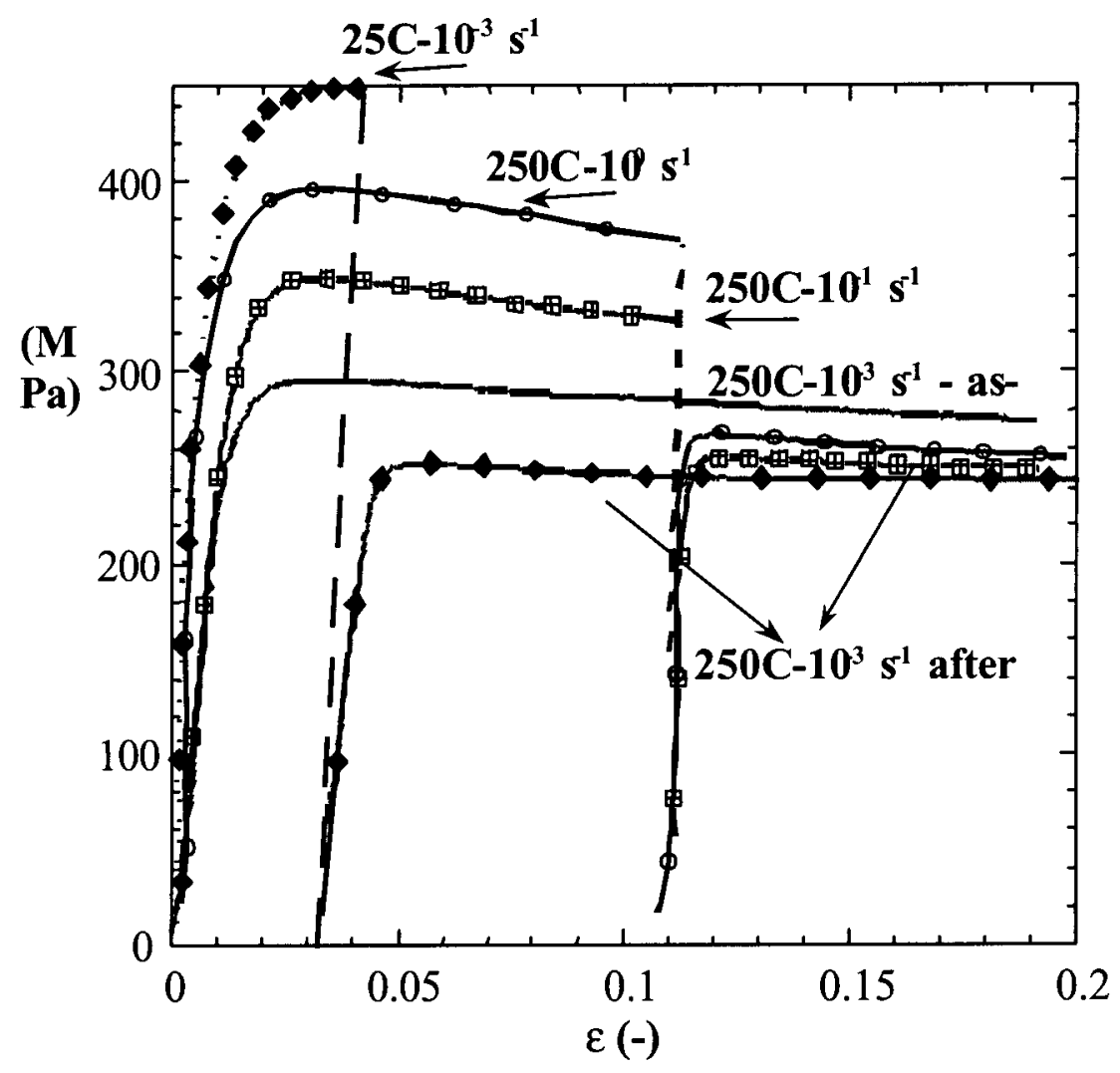

Figure 7: Effect of strain-rate history on the compressive flow behavior of composite $\mathrm{Clb}$. 
Typical true stress vs. logarithmic strain curves for the Chesapeake materials

Various temperature and strain rate conditions are shown and the values of stress and strain are absolute. Compression tests are conducted on samples with an aspect ratio (height to diameter) of 1.5 between tungsten carbide platens.
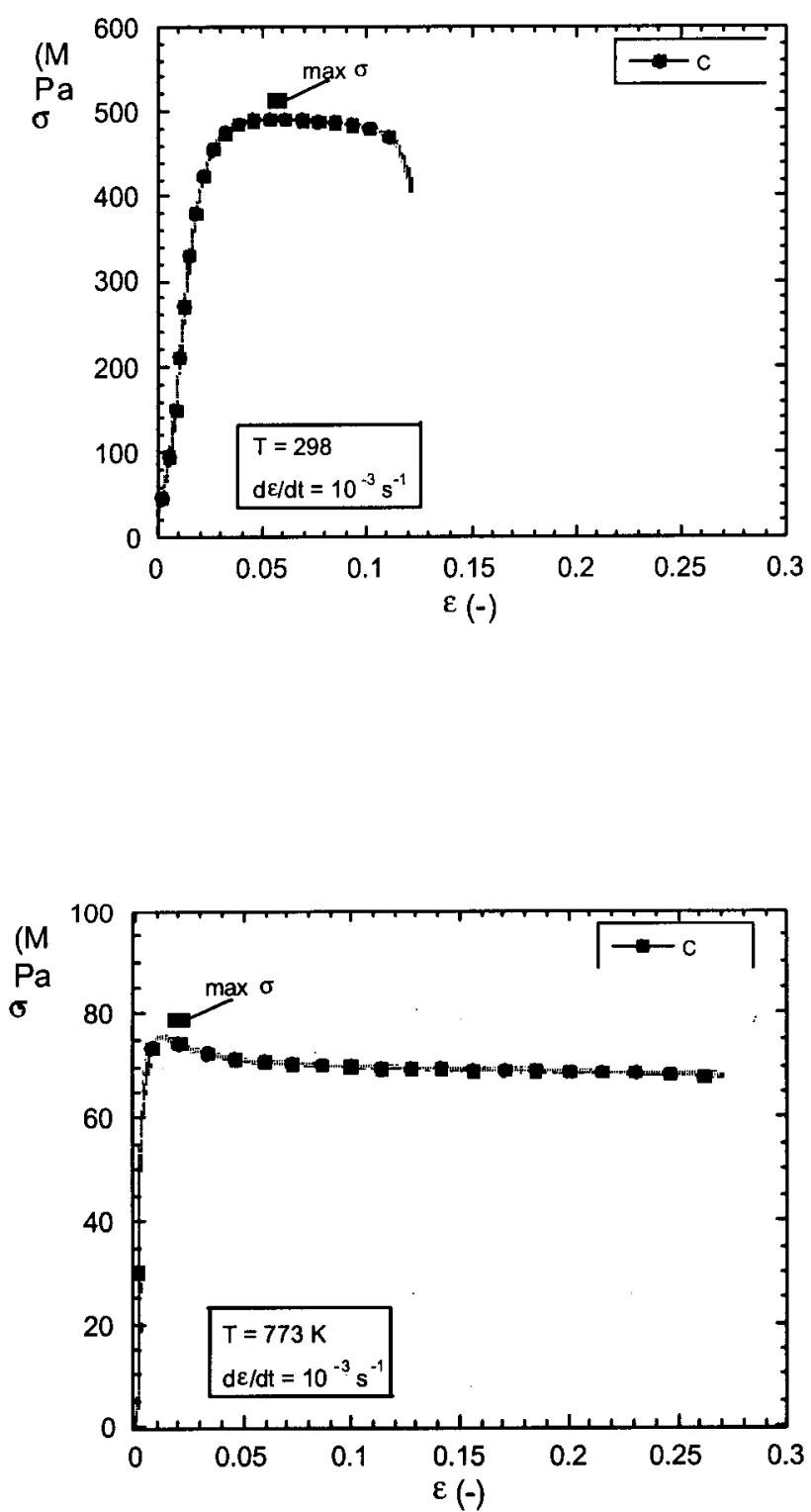


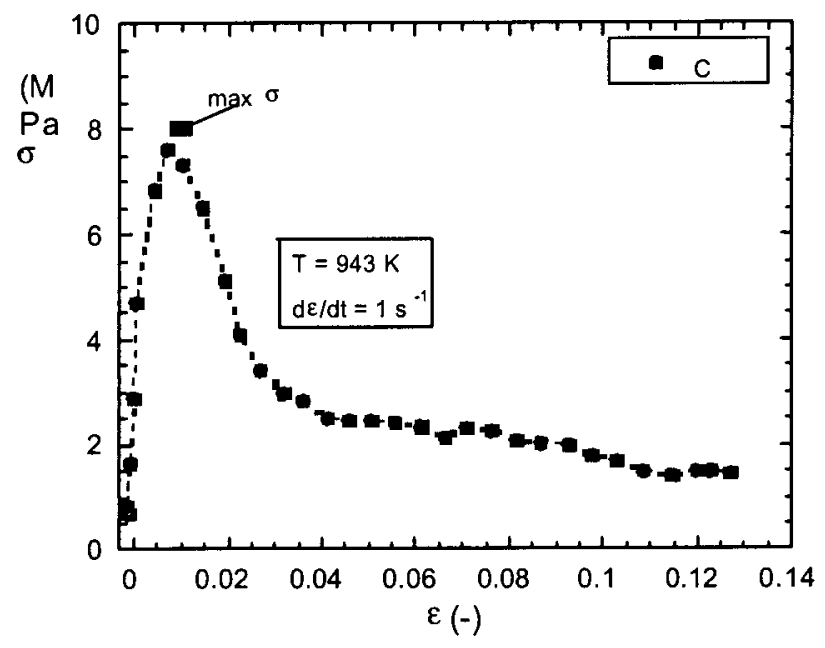




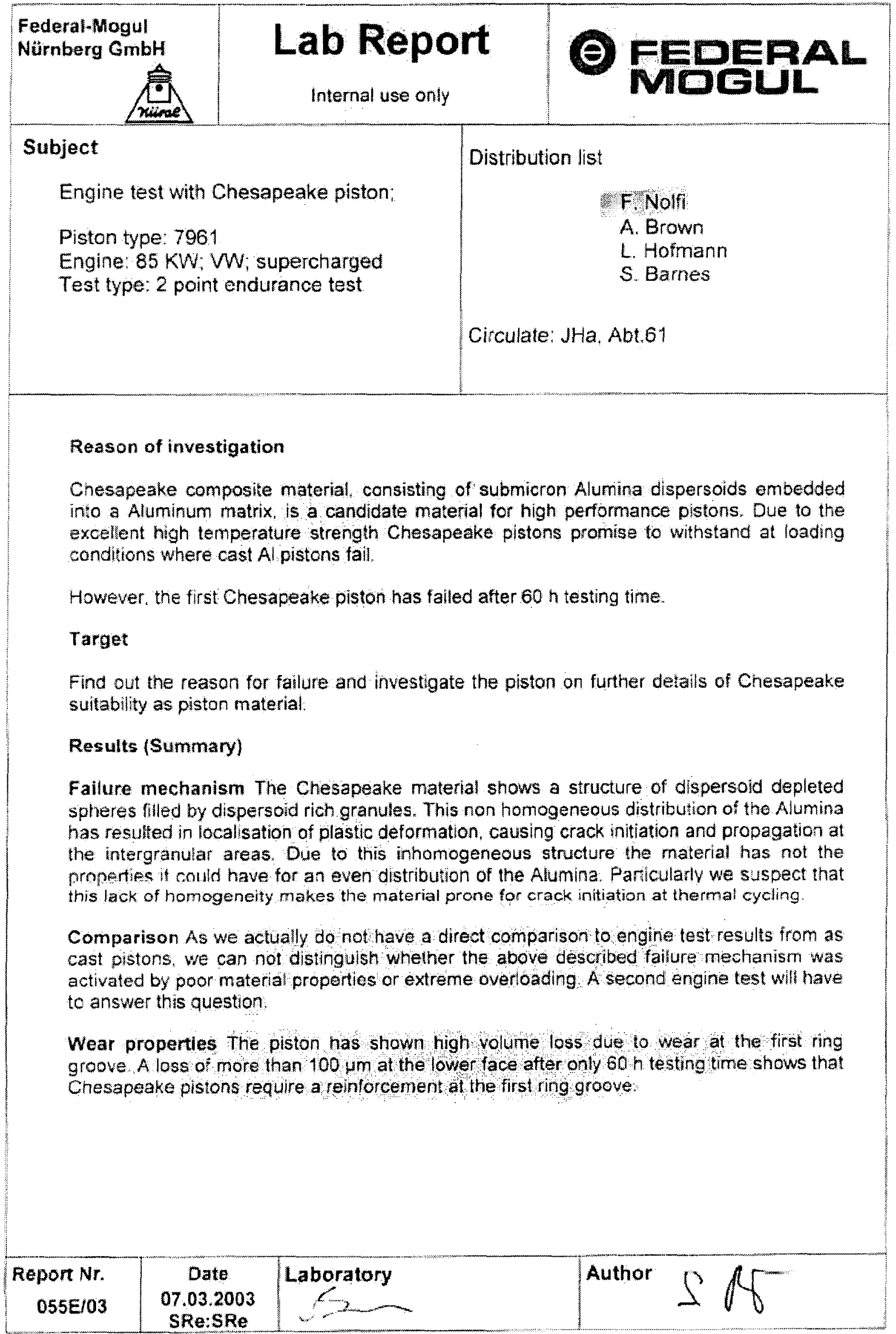




\section{Failure Mode}

- Cracking has occurred at the pin bore plane the area of highest mechanical loading (see Fig. 1)

- The cracks were initiated at both pin axis sices of the bowl edge (see Fig. 1)

- 3 different structures (named I. III) were found at the fracture surface (see Fig. 2):

1. Mainly cracking at plane of highest stresses but deflection of crack to granular surfaces at some places (see Fig. 3).

11. Crack propagation only at granule surfaces. Size of the granules is about $100 \mathrm{~mm}$ (see Fig, 4).

111. Very smooth fracture surface Crack has followed the plane of highest stresses without deflections by the material structure (see Fig. 5).

This three areas can be related to:

1. Crack initiation and propagation at high temperatures / low rates

II. Crack propagation at lower temperatures $/$ higher rates

III. Crack propagation at low temperatures/very high rates

\section{Inhomogeneities}

The fractured piston shows various indications for non homogeneous material behaviour:

- Preferred crack propagation at granular surfaces

- Type I and II fracture surface suggest structure of hard granules embedded into a soiter matrix (see Fig. 6...8)

- Optical and SEM images show a inhomogeneous structure of the piston material (see Fig. 9..12)

2. This inhomogeneities can by size and structure be closely related to the granular structure of the fracture surface

- Earlier investigations on Chesapeake material have revealed a structure of dispersoid rich granules embedded into a dispersoid poor matrix, 100 (see Fig. 13)

$\Rightarrow$ The material consists of harder and softer areas, resulting in localised plastic deformation and crack propagation at spherical surfaces

\section{Crack initiation}

- High thermal loaded and cycled parts of the piston (bowl edge) show details raised above the machined surface (see Fig. 14...17)

- As this details still show traces from the machining, they are not melting droplets

- The locations of surface modification as well as crack initiation can be related to the softer, dispersoid depleted areas of the material (see Fig 12)

$\Rightarrow$ We suspect the modifications of the machined bowl edge surface to be caused by localised plastic deformation of the softer areas of the material

- This localisation of plastic deformation enables or assists crack initiation

$\Rightarrow$ As this kind ot dispersoid depleted areas can not be detecled by FM standard processes, it must be avoided by the Chesapeake process

\section{First ring groove}

- Wear at the lower face of the first ring groove is about $100 . . .150 \mu \mathrm{m}$ after only 60 h engine testing (see Fig. $18 \ldots 19$ )

$\Rightarrow$ Chesapeake material can not withstand the conditions at the first ring groove

$\rightarrow$ Chesapeake pistons can not be produced without a solution for ring groove reintorcement 


\section{O FEDERAL Federal-Mogul Nürnberg MOEUL}

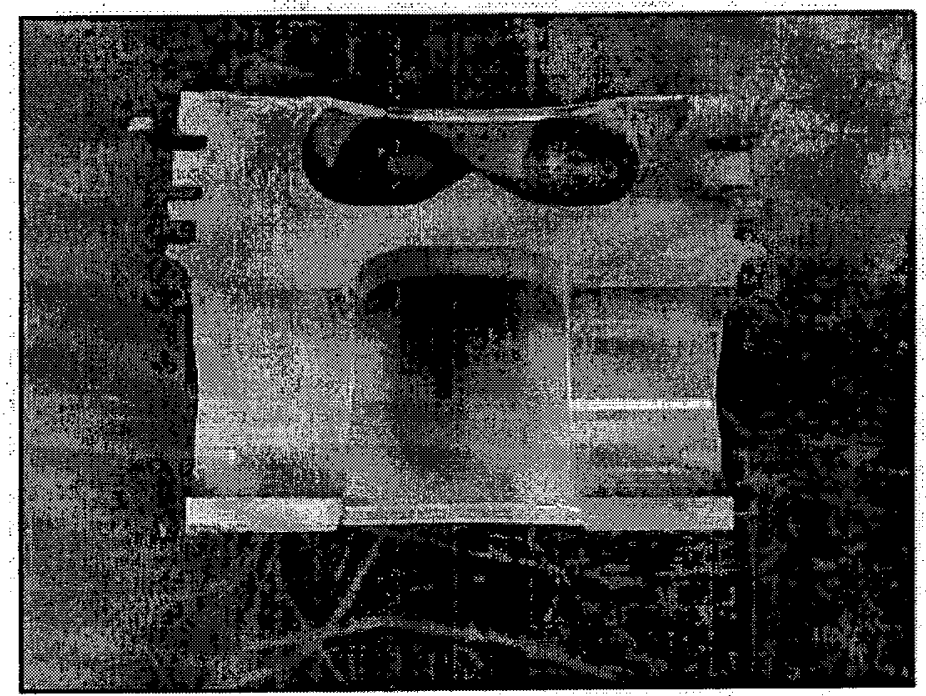

Vorgang:

P01174

Foto $\mathrm{Nr}$ :

$302 P 0598$

Chesapeake piston after $60 \mathrm{~h}$ engine testing; overview

Seite: won 6

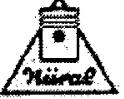

Abb: $: 1$

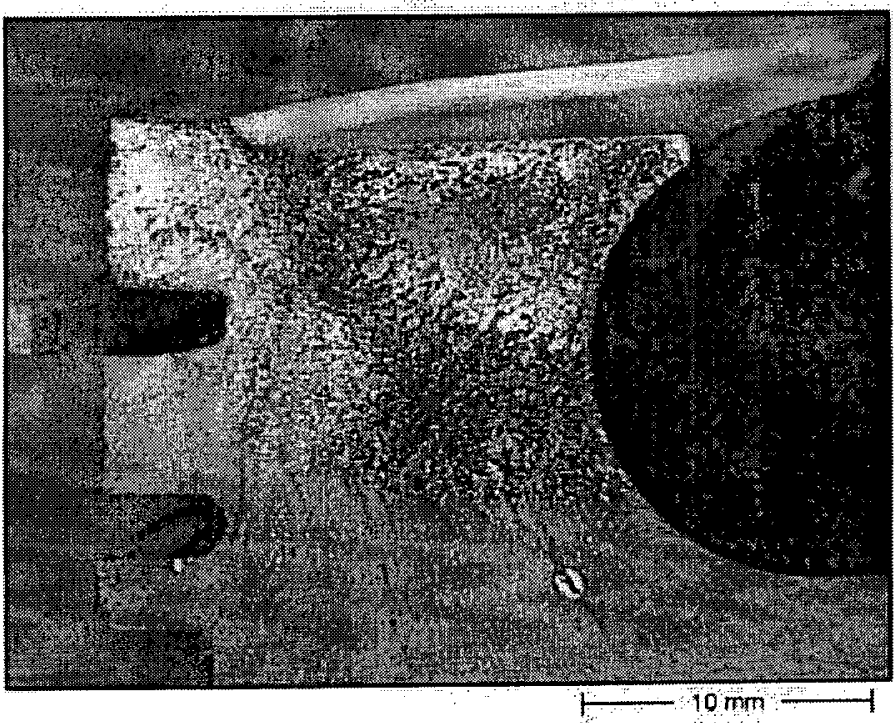

Vorgang:

P01174

FoloNr:

$302 P 0600$

Rissausgang am MR uber BoBo/MS; drei Bereiche mit yersohiedenem Bruchgefuge
Vorgang
P01.174
Foto $\mathrm{Nr}$.
$303 P 0002$

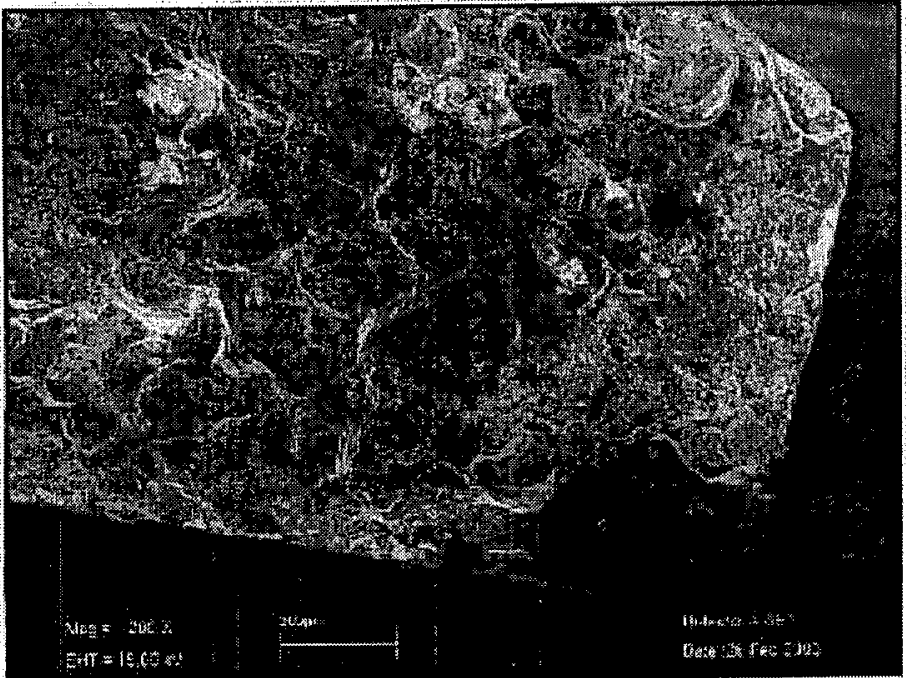




\section{O FEDERAL Federal-Mogul Nürnberg MOGUL}

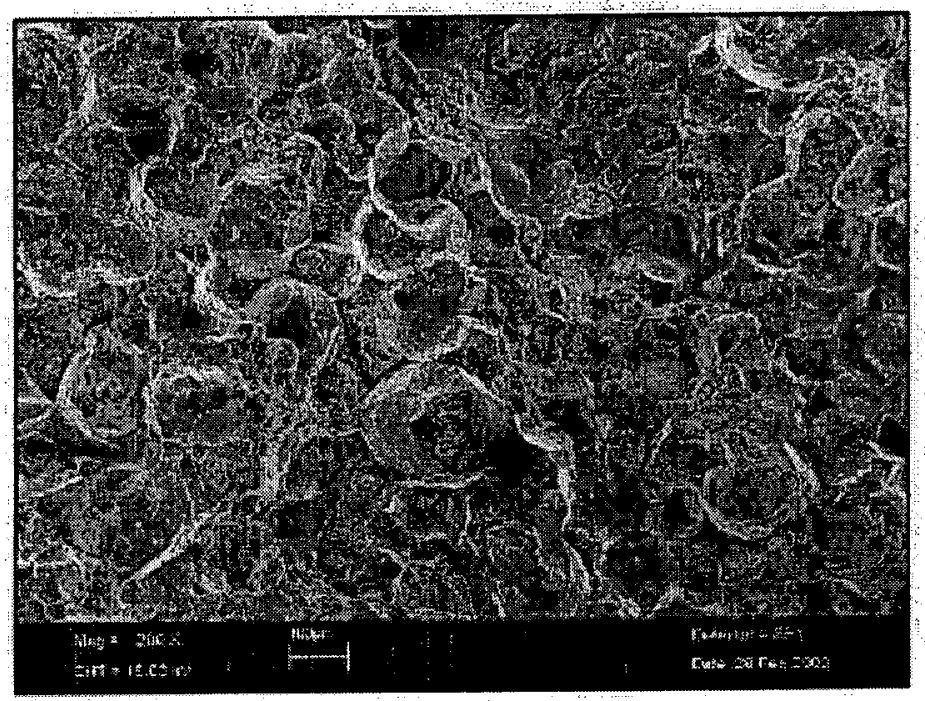

Vorgang:

P01174

Foto Nr.:

$303 \mathrm{P} 0003$

Abb: 4

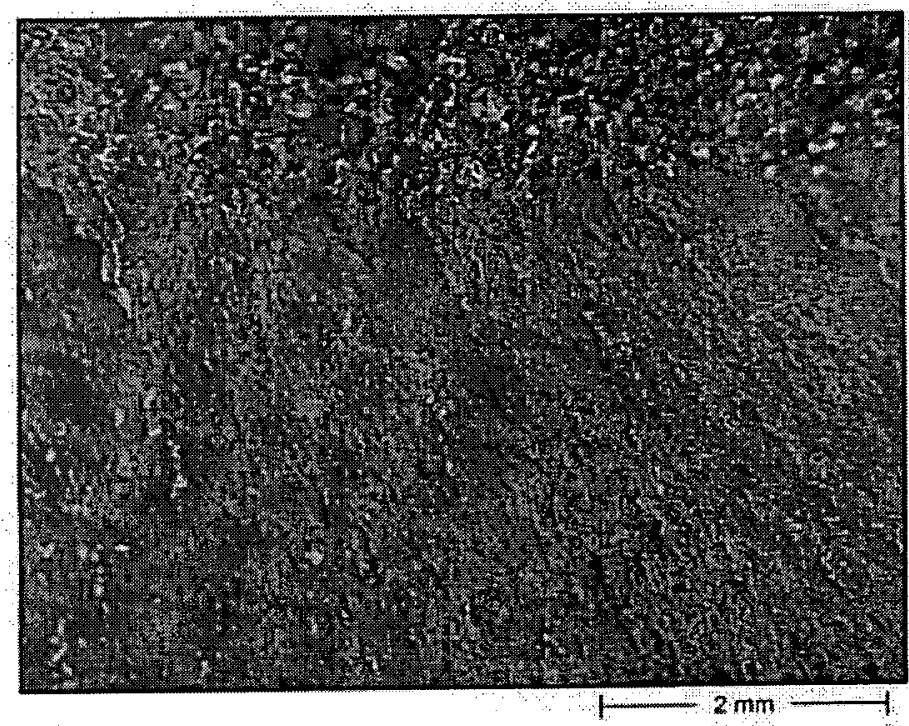

Vorgang:

P01174

Foto Nr.:

$302 P 0620$

Abb.: 5

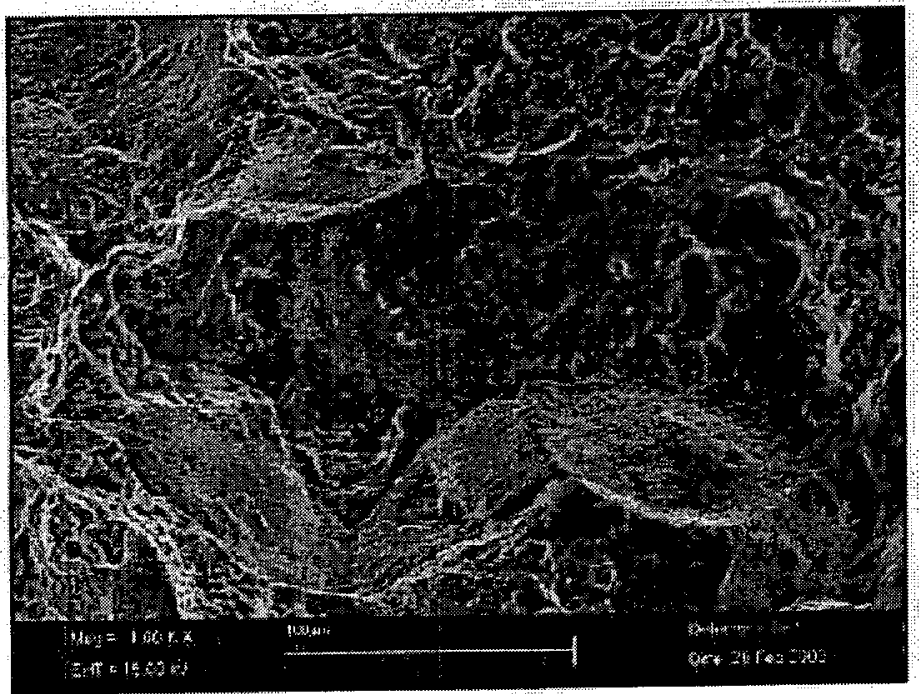

$\begin{array}{ll}\text { Vorgang: } & \text { po1174 } \\ \text { FotoNr: } & 303 P 0004\end{array}$

Ahh $\cdot 6$

3. Bereich (Gewaltbruch) mit Obergang von Bereich 2

in Bereich 3 sind keine Kugein mehr zu erkennen 


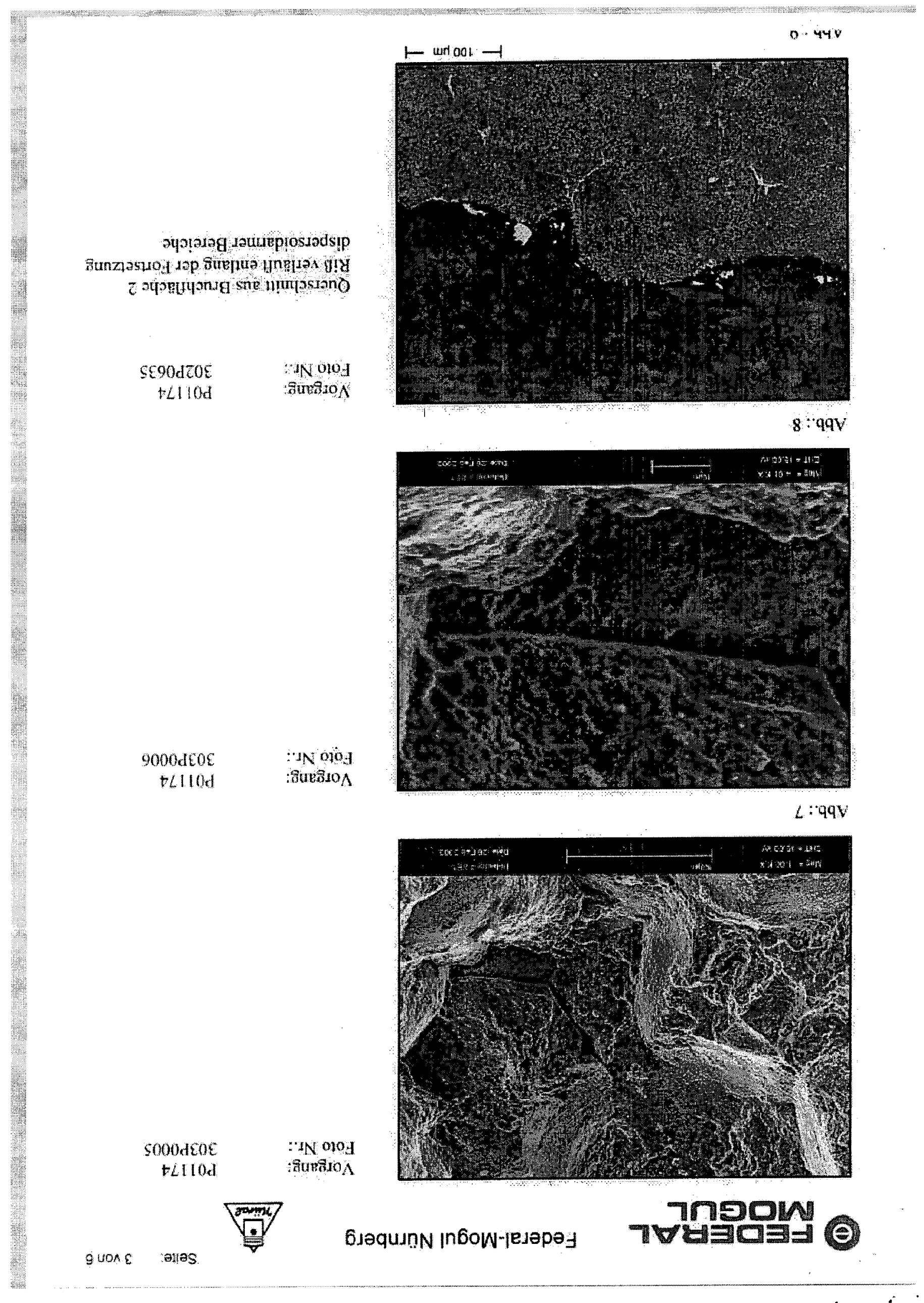




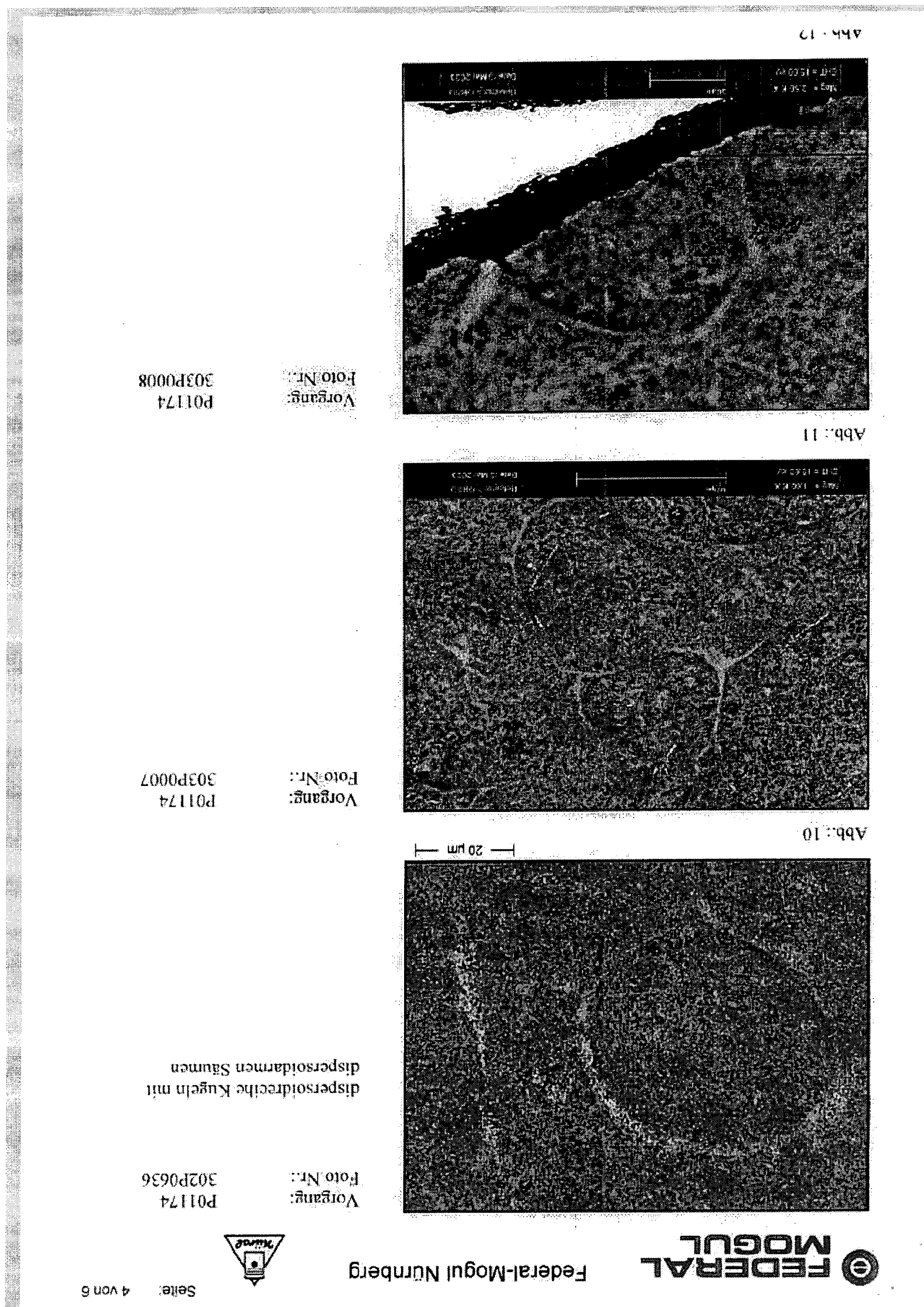




\section{O FEDERAL Federal-Mogul Nürnberg MOCUL}

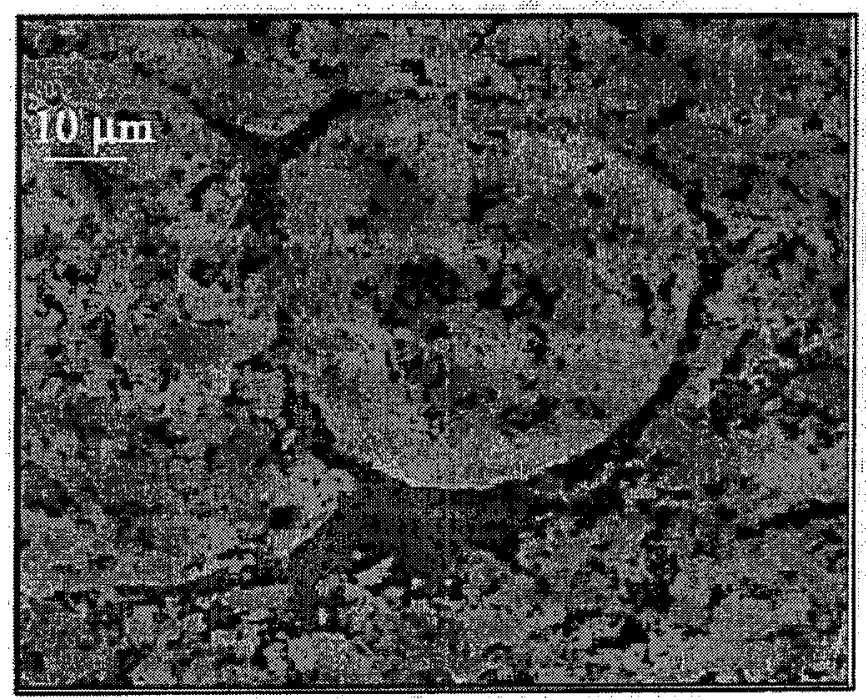

Vorgang:

P01174

Foto Nr.:

$303 \mathrm{P} 0009$

Abb.: 13

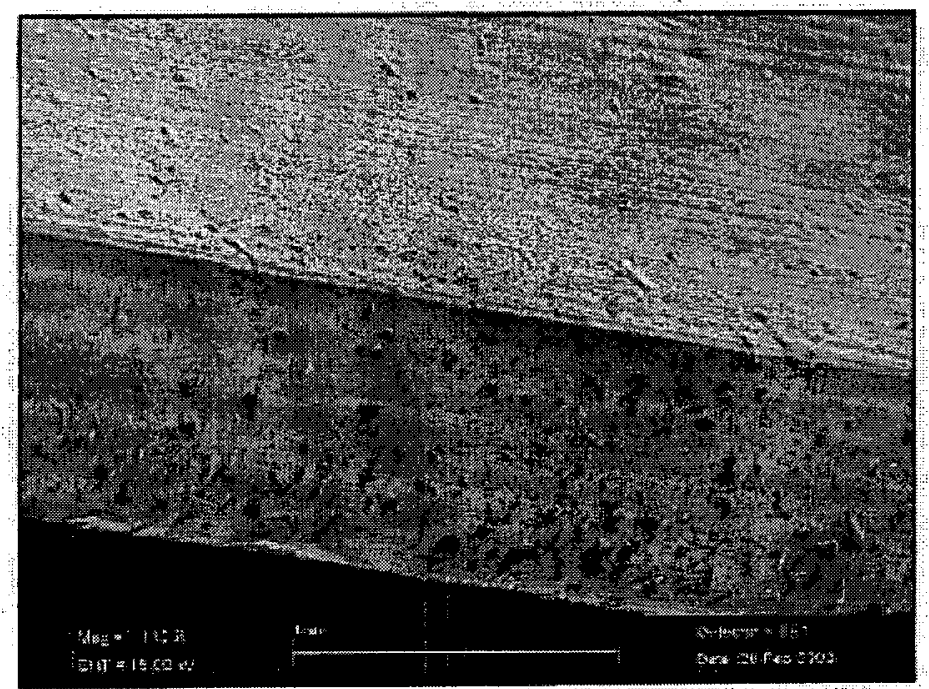

Vorgang:

P01174

Foto Nr:

303 P0010

Abb.: 14

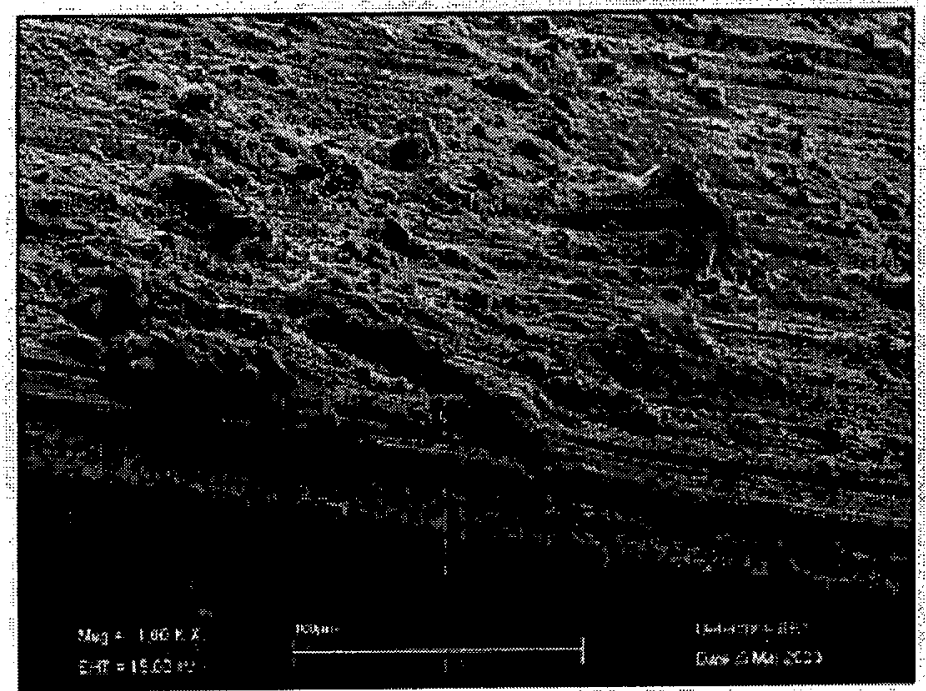

Vorgang:

Pol1174

Foto $\mathrm{Nr}$ :

$303 \mathrm{PO0I1}$ 


\section{(C) FEDERAL Federal-Mogul Nürnberg MOGUL

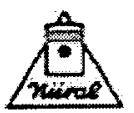

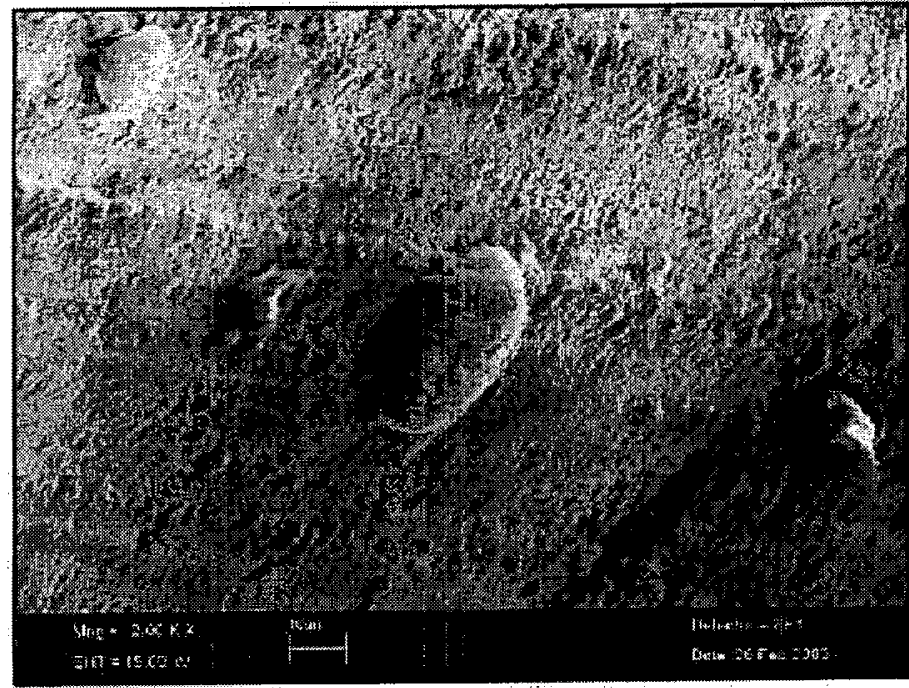

Vorgang:

Foto $\mathrm{Nr}$ :

Selte:

6 von 7

Abb.: 16

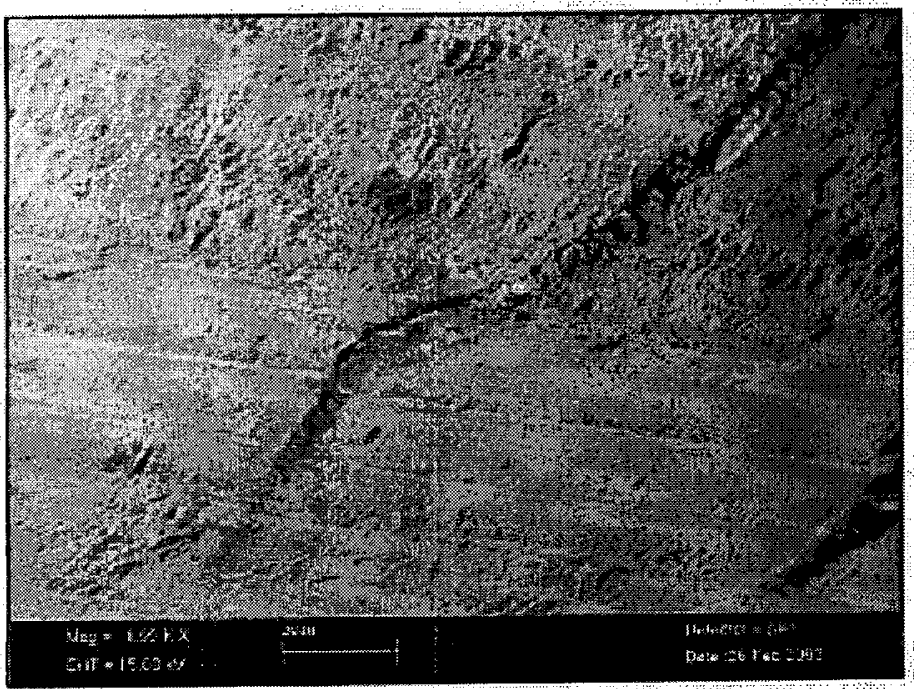

Vorgang:

P01174

Foto $\mathrm{Nr}$ :

$303 P 0013$

$\mathrm{P} 01174$

$303 \mathrm{P} 0012$

Abb. 17

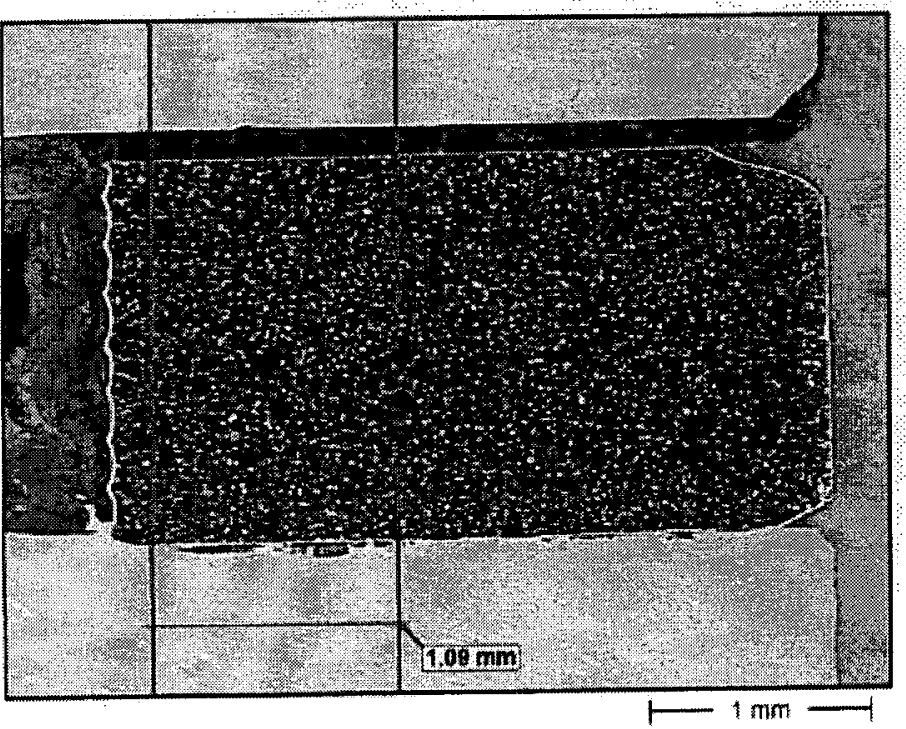

Vorgang:

P01174

Foto Nr.

$302 \mathrm{P} 0643$

Fester Ring in erster Ringnut 


\section{O FEDERAL Federal-Mogul Nürnberg MOGLL}

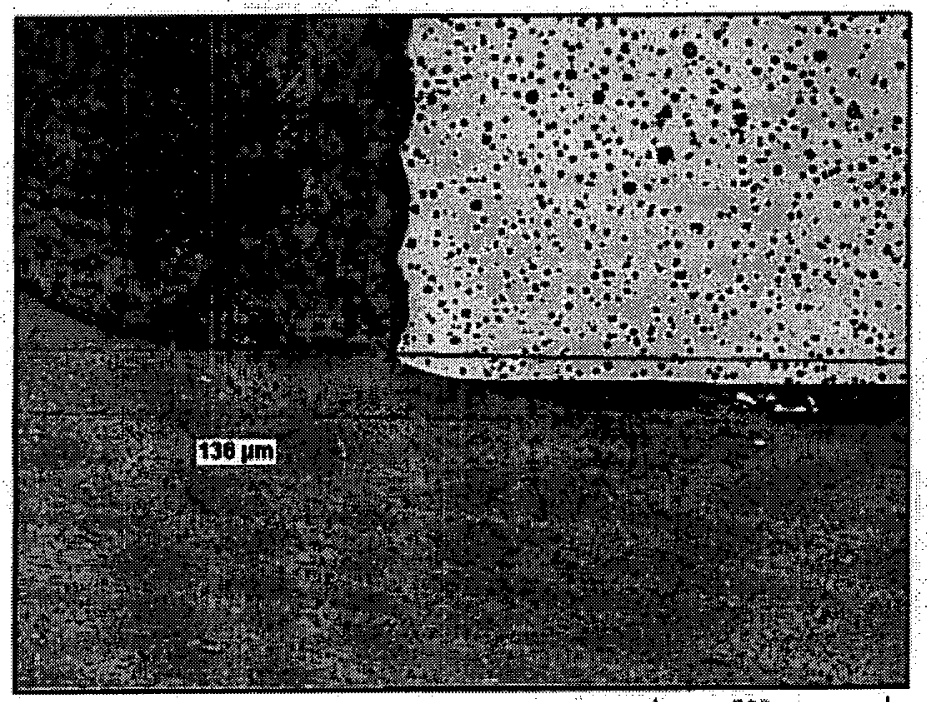

Vorgang:

Foto Nr:

$\mathrm{P} 01174$

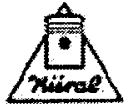

Sete:

$3 \operatorname{vin} 7$

Abb.: 19

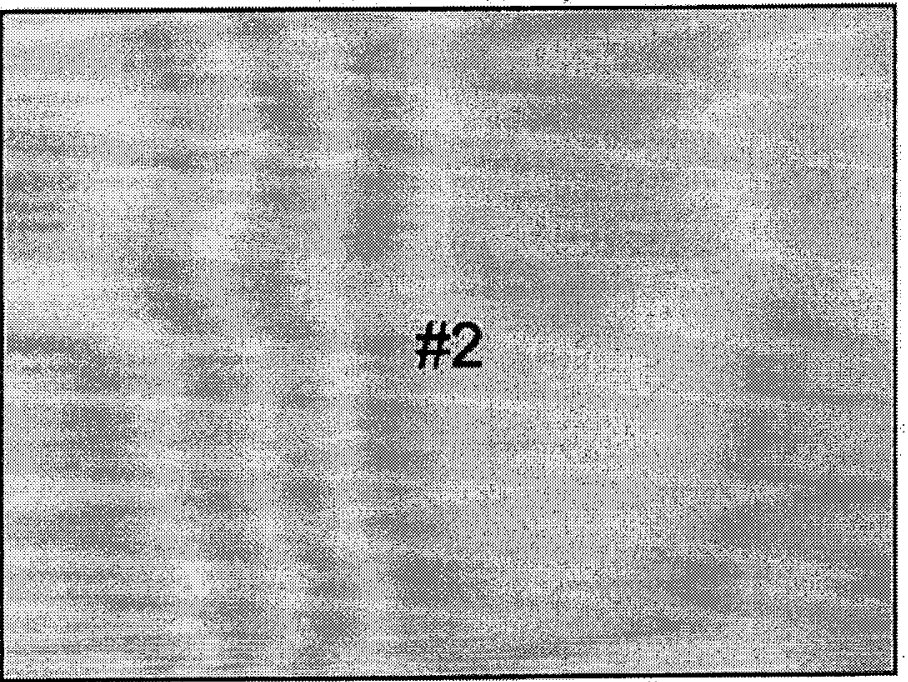

Vorgang: $\quad$ P01174

Foto Nr: $\quad$ QFotoNr2@

Interflanke von Nut 1;

erheblicher Verschleil schon nach $60 \mathrm{~h}$

aBildbemerkung $2 Q$

$\begin{array}{ll}\text { Vorgang: } & \text { pol174 } \\ \text { Foto Nr } & \text { afotoNr/3a }\end{array}$

(a) Bildbernerkung $3 a$

\section{\#3}

